\title{
Wave energy: Nostalgic Ramblings, future hopes and heretical suggestions
}

\author{
Stephen Salter ${ }^{1}$ \\ '...if you can bear to hear the truth you've spoken twisted by knaves to make a trap for fools...'
}

Received: 21 March 2016 / Accepted: 9 May 2016 / Published online: 5 July 2016

(c) The Author(s) 2016. This article is published with open access at Springerlink.com

\begin{abstract}
This study extends and updates a chapter in the book edited by Joao Cruz entitled Ocean Wave Energy: Current Status and Future Perspectives, Cruz (Ocean wave energy: current status and perspectives, Springer, Berlin, 2008). It outlines laboratory techniques and results from the first work on wave energy, which led to the Edinburgh duck. It then describes some of the work done on later devices at Edinburgh University. Some of the results and ideas for power conversion, component testing, and installation may be relevant to other wave energy designs and may help future generations of wave inventors to save time and avoid expensive mistakes.
\end{abstract}

Keywords Wave energy · Test-tank - Wavemaker · Longspine duck · Desalination · Hurricane · Digital hydraulics

\section{Wave energy at the University of Edinburgh}

In the autumn of 1973, the western economies were given the rare chance of a ride in a time machine and saw what the world would be like when there was no longer cheap oil. Most people thought it looked rather uncomfortable, but a few very powerful people made a great deal of money by exaggerating the crisis. Others, who had previously been regarded as eccentric, increased their efforts to develop what were then called alternative, and are now called renewable, energy sources. Still others set out to destroy what they saw to be a threat. In 1973, the main fear was a shortage of fossil fuels.

Stephen Salter

S.Salter@ed.ac.uk

1 School of Engineering, University of Edinburgh, Edinburgh EH9 3JL, Scotland, UK
In 2016, the growing fear is what fossil fuels are doing to the climate, especially to ice in the Arctic.

Waves were only one of many possible sources, and there are many possible ways in which waves can be harnessed. There are floats, flaps, ramps, funnels, cylinders, airbags, and liquid pistons. Devices can be at the surface, the sea bed, or anywhere between. They can face backwards, forwards, sideways, or obliquely and move in heave, surge, sway, pitch, and roll. They can use oil, air, water, steam, gearing, or electromagnetics for generation. They make a range of different demands on attachments to the sea bed and connections of power cables. They have a range of methods to survive extreme conditions but perhaps not quite enough.

Their inventors, myself included, invariably claim at first that they are simple and, after experience with the dreadful friction of reality, discover that this is not totally true when they come to test in the correct wave spectra with a Gaussian distribution of wave amplitudes. An easy way to detect beginners is to see if they draw waves the same size on both sides of their device.

Appeals to simplicity are widespread and have a strong appeal to non-engineers and, particularly, to political decision-makers and investors. However, it is hard to find any field of technology in which what is inside the box does not get steadily more complicated as it gets faster, lighter, cheaper, more powerful, and more efficient. The complications are all introduced for good reasons and, if the necessary hardware is properly researched, will produce good results. Who would abandon railways for wheel barrows because of the smaller number of wheels? Only a simpleton.

Many inventors of wave power devices, going back to Girard pere et fils in 1799, start with heaving floats. Apart from a brief flirtation with oscillating water columns, so did I. But I had the advantage of a workshop in which I could make any mechanical or electronic instrument that I was able 
to design and there was a narrow tank that I could borrow. As so often in physics and engineering, a full understanding of all the energy flows leads to a full understanding of the problem and points to suitable solutions.

It was necessary to make something against which a float could do work that could be accurately measured and compared with the energy transfers from incoming, transmitted, and reflected waves. While the Girards proposed the use of a ship of the line, I thought that it would initially be cheaper to begin with a length of $100 \mathrm{~mm}$ by $25 \mathrm{~mm}$ varnished balsa wood, just fitting inside the $300 \mathrm{~mm}$ width of a small wave tank. Rotating bearings are much nicer than translating ones. However, if they are at the end of a long arm, they give a good approximation to a translating constraint. If you grind a 70degree cone on the end of a length of tool steel and use it to punch the end of a light alloy or brass rod you get a beautiful socket into which you can place a 60-degree conical-point screw with friction acting at a very short radius. Grease will slow, if not stop, corrosion long enough for plenty of tests. The first heaving buoy model is shown in Fig. 1a.

For the power measurement, I used two very strong bar magnets in a magnetic circuit which excited two coils wound like an oversize galvanometer movement and linked together in a parallelogram using the same spike bearings pulled by elastic bands into cones in the end of a strut. The parallelogram could be coupled to the float with another strut and elastic band. These acted like a universal joint with very low friction and no backlash.
Moving the float generated a nice velocity signal in one of the coils. This could be amplified and fed back to the second coil with polarity chosen, so as to oppose the movement. Changing the gain of the amplifier would change the damping coefficient. A high gain made it feel as if it was in very thick honey. If the amplifier feedback connections are such that it delivers an output current proportional to the input voltage, then temperature changes in the galvanometer coils do not change the calibration.

From calculus, we know that the position of an object is the time integral of its velocity history plus some constant. If the signal from the velocity coil is put into an operational amplifier circuit connected as an integrator, we get an accurate position signal. If the parallelogram is moved backward and forward between the jaws of a vernier gauge, the integrator output signal will be a square wave. The field-effect transistor operational amplifiers of 1973 had low enough offset currents to allow this position signal to be read on a digital voltmeter. The force was calibrated by making the pushrod drive the pan of a weighing machine.

Measuring the waves could be done with a light float made from expanded polystyrene foam mounted on a swinging arm. A pair of microammeters, coaxial with the linkage bearings, with their needles glued to the float arms, gave a very clean velocity signal from even the smallest waves. Integrating float velocity gave an even cleaner wave-amplitude signal. The float took an average measurement across the width of the tank and, therefore, was insensitive to cross
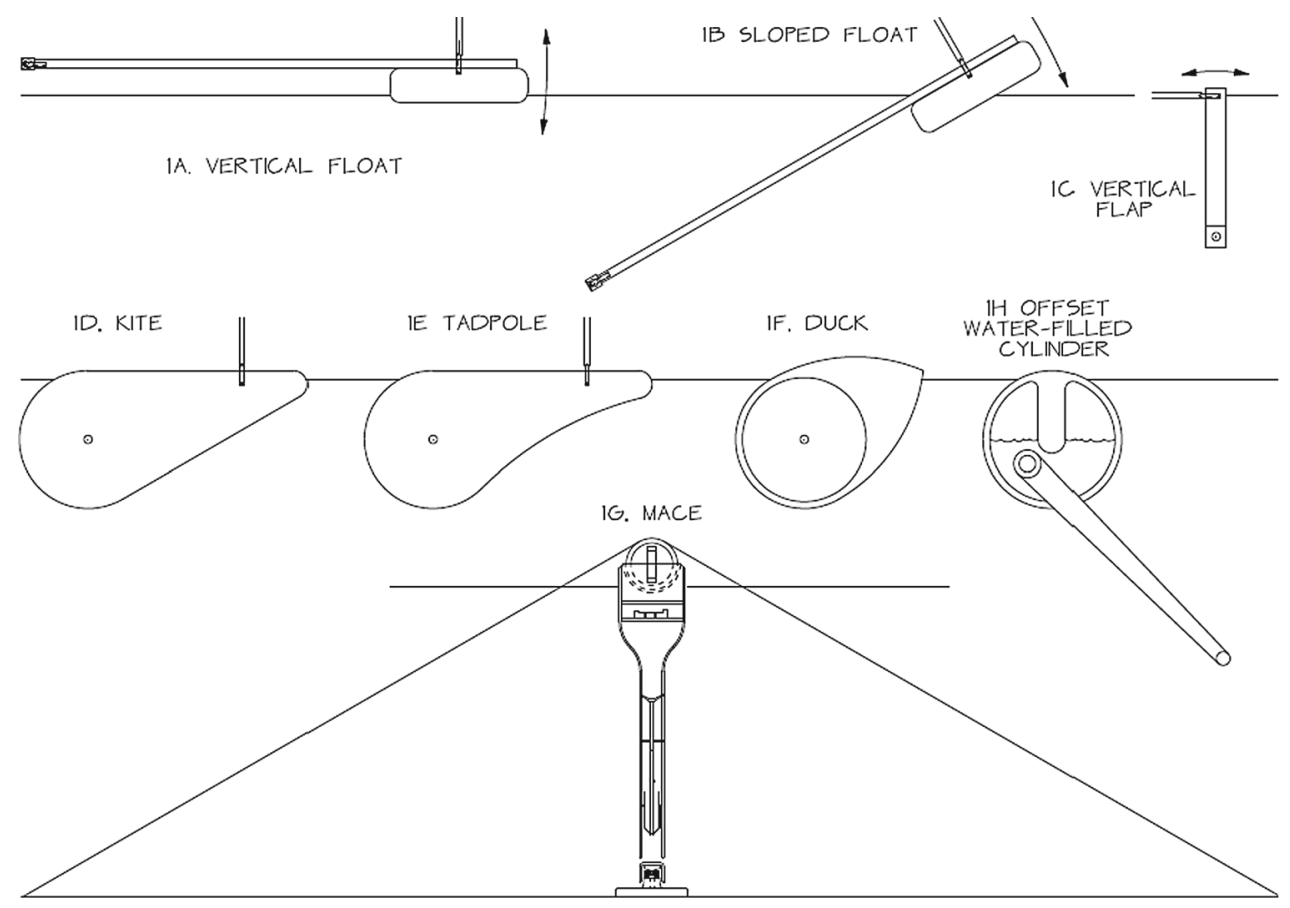

Fig. 1 In the beginning was a vertical heaving float 
waves which are nearly always present. It could measure waves down to $0.01 \mathrm{~mm}$ which we could not even see, far less than the meniscus hysteresis of resistive-wire gauges which we later had to use for very steep waves.

To calculate the power, you just multiply the instantaneous force signal by the instantaneous velocity signal, which will give you an offset sine wave at twice the wave frequency. You then take a long-term average with a low-pass filter.

This equipment allowed the measurement of model efficiency. The first result for the vertical heaving balsa wood float in Fig. 1a was disappointing-only $15 \%$ whatever adjustments were made to the damping coefficient. Some of the energy was reflected, but most went straight past the model. However, the depth of the hinge was very easy to adjust. If it was pushed down, so that the movement was along a slope as in Fig. 1b, the performance shot up to $50 \%$, much higher than most people would have predicted.

A vertical flap hinged below the water as in Fig. 1c could also be coupled to the dynamometer. This showed an efficiency of about $40 \%$ with $25 \%$ being transmitted on to the beach and $25 \%$ sent back to the wave-maker. It looked as though the horizontal motion of a wave, which almost all new wave inventors ignore, was better than the vertical one. Despite rich vocabularies of nautical terms, we have no word in any language for this movement of a wave.

The borrowed narrow tank had a commercial hinged-flap wave-maker with amplitude set by a crank radius and frequency set by a mechanical variable-speed mechanism. One problem was that there was no way to make mixed seas. However, a more serious one was that the drive to the flap was rigidly fixed by the crank eccentricity, so that the flap reflected waves just like a rigid vertical cliff. Test tank beaches are not perfect, and the first designs of any wave device are likely to reflect a substantial fraction of the incoming waves. It was even worse, because the amplitude of a wave created by a hinged flap for a given angular movement depends on the square of the depth of the hinge, and this would be increased during the crest of any reflection and reduced during the trough, together with some Doppler shifting. Even if we could not make irregular waves with the spectrum of our choice, the tank reflections would make one with a spectrum of their own. Trying to make a regular wave could lead to amplitude variations of three to one and power variations of nine to one.

The vertical flap showed that it was wrong to allow the model to transmit waves behind. Was it possible to make a model with a front but no back? Figure 1d shows an attempt, code-named Kite. This showed an efficiency of $70 \%$ and very low onward wave transmission. Figure 1e shows the model code-named Tadpole, which was meant to allow the circular motion of water particles to continue but had the same result. However, waves are very good at sending energy to the next volume of water with almost no loss: the idea of allowing

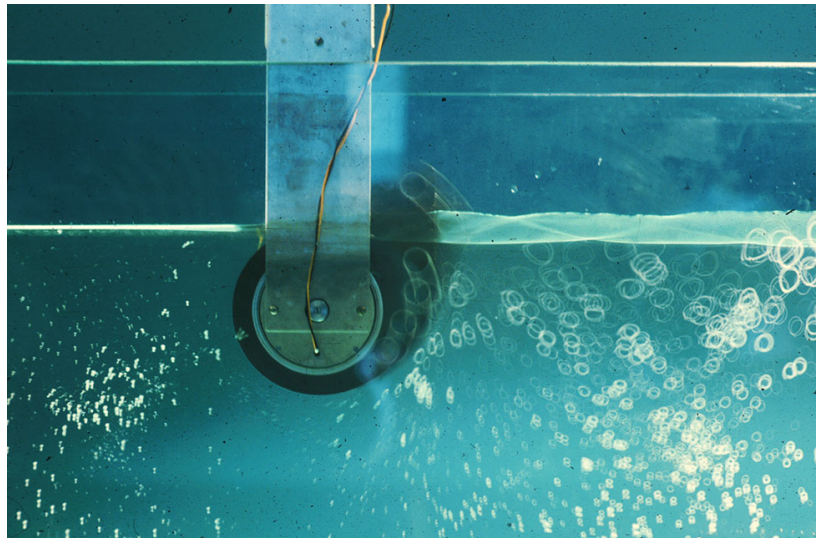

Fig. 2 Jamie Taylor's photograph taken in 1976 which convinced people who really knew about waves that high efficiency could be achieved

the water motion to continue in the way it would do in the absence of a model was powerful. Could the circular backs of Fig. 1d, e be combined with a front shape which allowed the decaying orbital motion of water particles to take place just as it would in the open sea?

I asked a computer-minded Ph.D. student, Peter Buneman, to help while I struggled with a slide rule and drawing board. We converged on the same shape shown in Fig. 1f, codenamed Duck. Its efficiency was measured at $90 \%$, which even we did not believe despite many calibrations cross-checked by Jim Leishman from the National Engineering Laboratory, Gordon Goodwin from the Department of Energy and Brian Count from the CEGB, then the big English electricity monopoly. Later, photographs by Jamie Taylor in Fig. 2 allowed visual proof that the calibrations were correct. It is a one-second exposure of a duck model on a fixed mounting in a narrow tank. The two wires are connections to part of an electromagnetic dynamometer, which is absorbing power. Waves are approaching from the right. Drops of a neutrally buoyant tracer fluid consisting of a mixture of carbon tetrachloride (a nasty green-house vapour, now illegal) and xylene with titanium oxide pigment have been injected to show the decaying orbits of wave motion.

The amplitude of the incoming waves can be measured from the thickness of the bright band on the right. Nodes and antinodes due to the small amount of reflection are evident. However, the thickness of the bright band to the left of the model is largely due to the meniscus, as is confirmed by the very small orbits of tracer fluid in this region.

As the energy in a wave is proportional to the square of wave amplitude, we can use the photograph to do energy accounting. If nodes and antinodes show that the reflected wave is one-fifth of the amplitude of the input, it would have one twenty-fifth, or $4 \%$, of its energy. This means that $96 \%$ has gone into the movement of the test model. The dynamometer showed that just over $90 \%$ of the power in the 
full width of the tank had been absorbed by the power takeoff, leaving $6 \%$ losses through viscous skin friction and vortex shedding. We joked that the rate of improvement might slow because of some impenetrable barrier around $100 \%$.

One should be careful about such jokes. Budal and Falnes (1975) in Trondheim had found that point absorbers in wide tanks or the open sea could absorb more energy than was contained in their own geometrical width, just as the signal from a radio aerial does not depend on the wire diameter. The terms 'capture width' and 'capture width ratio' replaced efficiency for solo devices in wide tanks. The Falnes Budal findings were simultaneously and independently confirmed by David Evans at Bristol and by Nick Newman and Chiang Mei at MIT.

Because absorbing energy from waves was the whole objective and making waves was very similar to absorbing them, it seemed an obvious step to build a wave-maker with the same control of force and velocity as an absorbing model. The motors available then had too much brush friction to allow the use of current as a control, so a force-sensing strain gauge was built into a drive arm. A tachogenerator measured the velocity. The displacer was the same shape as a duck but with a hollow cylindrical interior to avoid the large vertical buoyancy force. The shape was rather expensive to make in the large numbers planned for a wide tank and later versions used flaps with a textile rolling-seal gusset to maintain a 'front with no back'. Either design allowed the generation of very accurate waves even with $100 \%$ reflecting models and gave repeatability and stability to one or two parts per thousand.

Force-sensing does not suffer the phase lag, $90^{\circ}$ at about $8 \mathrm{~Hz}$, of the meniscus of a wire wave gauge. It takes an average measure across the entire wave-maker. It provides a stiff drive path, so that high loop gains can be achieved. Using force and velocity to control energy and giving that energy to the water at the right frequency, we allow the water to choose the shape of wave that it likes to transmit that energy even if what are called 'evanescent modes' have the wrong waveform close to the wave-maker. The chief design problem is getting rid of any friction that could corrupt the force measurement. Many more absorbing wave-makers (1300 and counting) have been sold by a spin-off company, Edinburgh Designs, run by Matthew Rea. ${ }^{1}$

The next task was to widen the band of high efficiency and move it to longer wave periods, equivalent to having a smaller device. This was done by Jamie Taylor who used systematic variations of the hub depth, ballast position and power takeoff damping for various duck shapes. We built a sliding mounting with a clamp and adjustable stop, which allowed one person

\footnotetext{
${ }^{1}$ Unpublished Edinburgh wave power project reports can be downloaded from the folder /Wave energy/Old reports at http://www. homepages.ed.ac.uk/shs.
}

to remove and reinstall a model to the exact position using only one hand in three seconds. Installation is likely to be harder, slower, and more expensive at larger scales. The models had tubes running through them into which stainless steel rods of various lengths could be inserted to adjust ballast. They had Aeroflex moving-magnet torque-motors at each end. One gave a velocity signal which could be processed by analogue operational amplifier networks built by David Jeffrey to give an opposing torque. This could implement variable damping, torque-limiting, positive or negative spring and inertia, indeed any power takeoff algorithm we could specify. Glenn Keller built an accurate gyro simulator.

Analogue multipliers needed for power calculations can perform a useful job with large input signals. The usual transfer function is $0.1(\mathrm{~A} \times \mathrm{B})$. With 10 volts on both inputs giving 10 volts output, an error of 100 millivolts is only $1 \%$ and would be tolerable. However, if A and B are only 1 volt, the product is 0.1 volts and the error is $100 \%$. The solution is to arrange a system of pre-amplifiers and post-attenuators on a double-bank rotary switch before and after the multiplier and manually adjust gain and attenuation, so that the two input signals do not quite clip. Modern digital electronics offers a complete solution.

To measure waves, we used a pair of heaving-floats on mountings which could be clamped to each other at distances of one quarter or three quarters of a wavelength. The pair could slide along ground stainless steel rails aligned parallel to the calm water surface. This rail alignment had been done with a capacitance proximity sensor and fine adjustment screws with everything finally locked by a metal-filled epoxy putty. The sensor was just sensitive enough for us to pretend that the rails followed the curvature of the earth rather than being quite straight. By sliding the pair of gauges to the position which maximized the difference of their outputs, we could put one gauge on a node and the other on an antinode. Half the sum gave the amplitude of the incoming wave and half the difference gave the amplitude of any reflection.

If we set a very high damping coefficient, the model would be locked almost stationary and would reflect nearly all the incoming energy like a cliff with an antinode at its front surface. If we set the damping to zero, it would move violently but still reflect with a node at the front. It was easy to find the best match, because David's electronics (Jeffrey et al. 1976) could calculate the instantaneous efficiency and Jamie would know immediately if his choice of damping, hub-depth, or ballast position was good or bad. He would have acceptably accurate measurements for a new test after about 40 seconds. This is much better than saving lots of data for subsequent processing.

Playing with different damping settings showed that wave devices were like loads on transmission lines which should be matched to the line impedance. A mismatch by a factor 
of two either way was tolerable but more than this would progressively lose much more output from reflections.

By integrating the velocity signal with a very low drift operational amplifier, we could get a good position signal and we could combine either polarity of this with the damping feedback signal to get positive or negative spring. Although this needed a small investment of energy back to the model, it was repaid with large interest, widening the efficiency band and moving it to longer waves. Rapid changes with rapid results make for rapid progress. Jamie Taylor pushed the performance band from a peak at a wavelength of four duck diameters to fifteen diameters with creditable performance at twenty-five.

David Jeffrey built two more electronic systems which turned out to be immensely useful and should be copied by others, perhaps using computer graphics. We had nearly sixty signal sources from wave gauges and the model that could be sent to thirty signal destinations, such as meters, signal processors, and oscilloscope displays. Getting any connections confused could negate an entire experiment and waste days of work. David built a pin-board matrix with signal sources along the top and destinations along the left vertical. Any source could be connected to any destination by the insertion of a pin at the corresponding intersection of row and column. A new experiment could be planned, set up, and checked in about a minute with first results a minute later.

The second system was a display of two oscilloscopes. One had a long-persistence phosphor, while the second had a storage tube which used electrostatic technology to retain a trace for about an hour. The conventional oscilloscope time-base was replaced by one which was locked to the wavemaker drive frequency. Phase is of vital importance in many areas of energy research but vital in work on waves. The sweep time was exactly the full wave period but also the start of the trace was always at an upward zero crossing of a wave, the crest always at $25 \%$ of the screen width and the trough always at $75 \%$. We could also plot any variable against any other.

When the long-persistence tube showed that the tank conditions were steady, the press of a button would write the next trace to the storage tube. The conditions could be changed for the next test and the next trace written. Provided we could finish a series within the tube storage time we could build up families of curves, and take Polaroid photographs such as the ones in Fig. 3.

This shows torque-to-angle diagrams for variations in damping, torque limit, and reactive loading with negative spring. The area inside the loop measures useful work. These diagrams are analogous to pressure-volume indicator diagrams for steam engines.

Another very useful commercial instrument was a transferfunction analyzer which combined a very accurate, crystallocked low-frequency signal generator with two digital voltmeters giving the in-phase and quadrature magnitudes of signals at that frequency or at harmonics of it.

The control desk allowed two people to sit in comfort within reach of every control knob and with eyes at wave level. It is shown in Fig. 4. Some people think that this photograph was contrived, but this was the actual working setup used every day. Despite enormous advances in digital com-

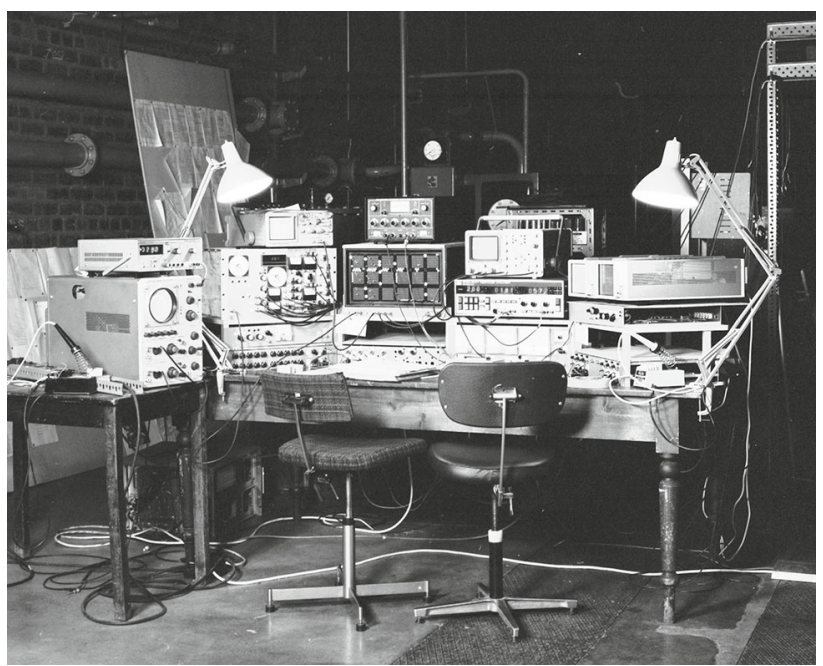

Fig. 4 The all-analogue tank control-bench with direct-reading efficiency calculation, pin board, transfer-function analyzer, and wavelocked pair of oscilloscopes
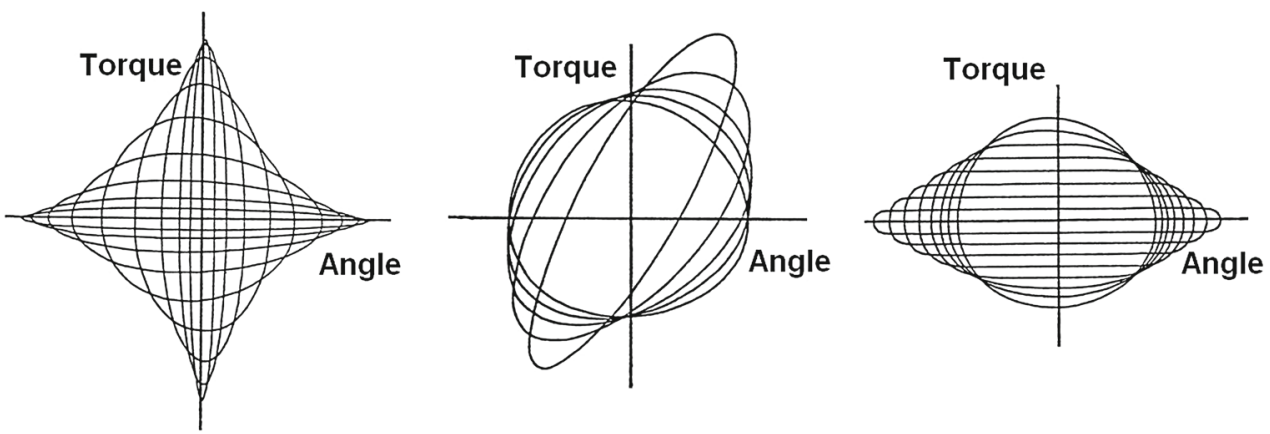

Fig. 3 Families of Lissajous plots of duck torque against angle for variable damping, variable amounts of negative spring giving reactive loading, and a selection of torque limits. These are from actual oscilloscope photographs of signals from tank models 
puting power since 1976 and wonderful data collection and analysis software, I have never since worked with such a fast and convenient tank control system as one using entirely analogue electronics. The Jeffrey circuit diagrams can be downloaded from Jeffrey et al. (1976). I advise tank testers to copy the interface on the screens of the computers of today.

Until then, all data analyses had been performed with the Hewlett Packard HP 65 hand-calculator which had a magnetic strip reader that could store programmes with as many as 64 steps. To work with multiple spectra, we went to the dreadful expense of $£ 7000$ to get a Tektronix 4051 computer which had an enormous memory of 16k, a graphics display and even a cassette tape reader for programmes and data. This cost the annual salaries of three research associates but allowed measurements of every possible wave and model signal in realistic wave spectra.

If the large forces from waves are to do useful work, there must be some reaction path to oppose them. By now, we knew enough about wave forces to realize that providing this with a rigid tower for the largest Atlantic waves in deep water would be very expensive and we wanted a way in which the structures would never be stressed to any level above that which would arise at their economic power limit. We wanted something that would experience large forces and high relative velocities in small waves but not in large ones. If the reaction frame could move $27 \mathrm{~m}$ in a $30-\mathrm{m}$ wave the ducks would think that, yet again, they were in 3-m waves working at the optimum power limit.

The only solution for deep water seemed to be a spine long enough to span many wave crests to get stability but with joints that could flex before the bending moments could cause any damage. We needed to know how such an elastic and yielding system would behave. We built the nearest approximation to replicate a short section of a very long spine in a narrow tank. It was a mounting called a pitch-heave-surge rig, shown in Fig. 5, which allowed the support stiffness,

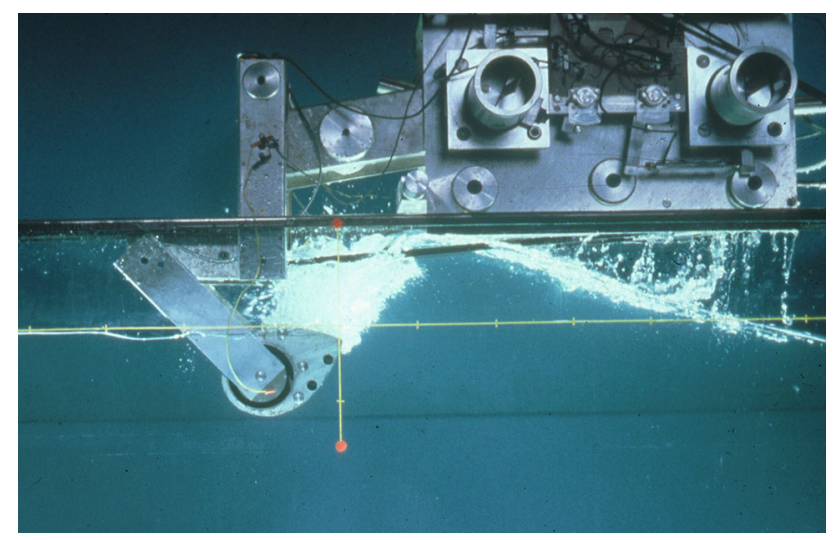

Fig. 5 The hundred year wave with maximum possible steepness achieved by selection of the phases of a mixed sea hitting a duck on a locked pitch-heave-surge rig damping and inertia to be set to any desired value but also to yield at forces above a chosen value. It could also be used to drive a model in calm water to measure the relationship between force and velocity, so as to give hydrodynamic coefficients of damping and added mass.

The rig proved to be ideal for testing the Bristol cylinder invented by Evans (1976), Evans et al. (1976) and Clare et al. (1982). Whereas we had worked for days to discover the best ballast position and power takeoff settings of a new model shape, he was able to calculate directly what the values should be. We already had a 100-mm diameter neutrally buoyant cylinder which we had used for force measurements. We set the stiffness and damping to his values and the model achieved almost $100 \%$ efficiency immediately. The Bristol cylinder does this by combining movements in both horizontal and vertical directions, so that a long wave, which might be expected to propagate below the cylinder, is cancelled by the wave generated by the cylinder movements. David Evans suggested that this would also be true for our duck system and so it was. The long-wave performance could be greatly improved by reducing the mounting stiffness. A demonstration can be seen at $3 \mathrm{~min} 10 \mathrm{~s}$ into the video which can be downloaded from http://www.youtube. com/watch?v=_bdeNuRF-yE. Fortunately the correct stiffness values were lower than those that could be supplied by post-tensioned concrete at full scale.

Jamie Taylor explored the effects of mounting stiffness and produced a map with two regions of high efficiency separated by a valley of very low efficiency at a particular heave stiffness. We called this Death Valley. The angular movements of the duck and its movement relative to the water surface could be reduced to almost zero in quite large waves. This could be very convenient for gaining access in small and medium sea states.

Computers are like bacteria. Once you have one it breeds others at exponentially increasing rates. The Tektronix was joined by a Commodore Pet which could generate seas in which the phases of each component could be combined with cunning malevolence to produce extreme wave events such as those as shown in Fig. 6. These are the result of freak waves hitting the model placed at a series of positions relative to the nominal break point. It could also trigger flash photographs at any time with microsecond precision. Figure 7 shows a sequence taken at intervals corresponding to one second at full scale. The force records plotted as heave against surge forces for all the test positions are shown in Fig. 8. It was a surprise to discover that there was a strong downward and seaward tendency, the most dramatic production of white water could occur with quite low forces, and the peak force occurred during the second wave trough following the instant of wave breaking. We clocked up half a million year's worth of hundred-year waves. Any developer who does not follow 

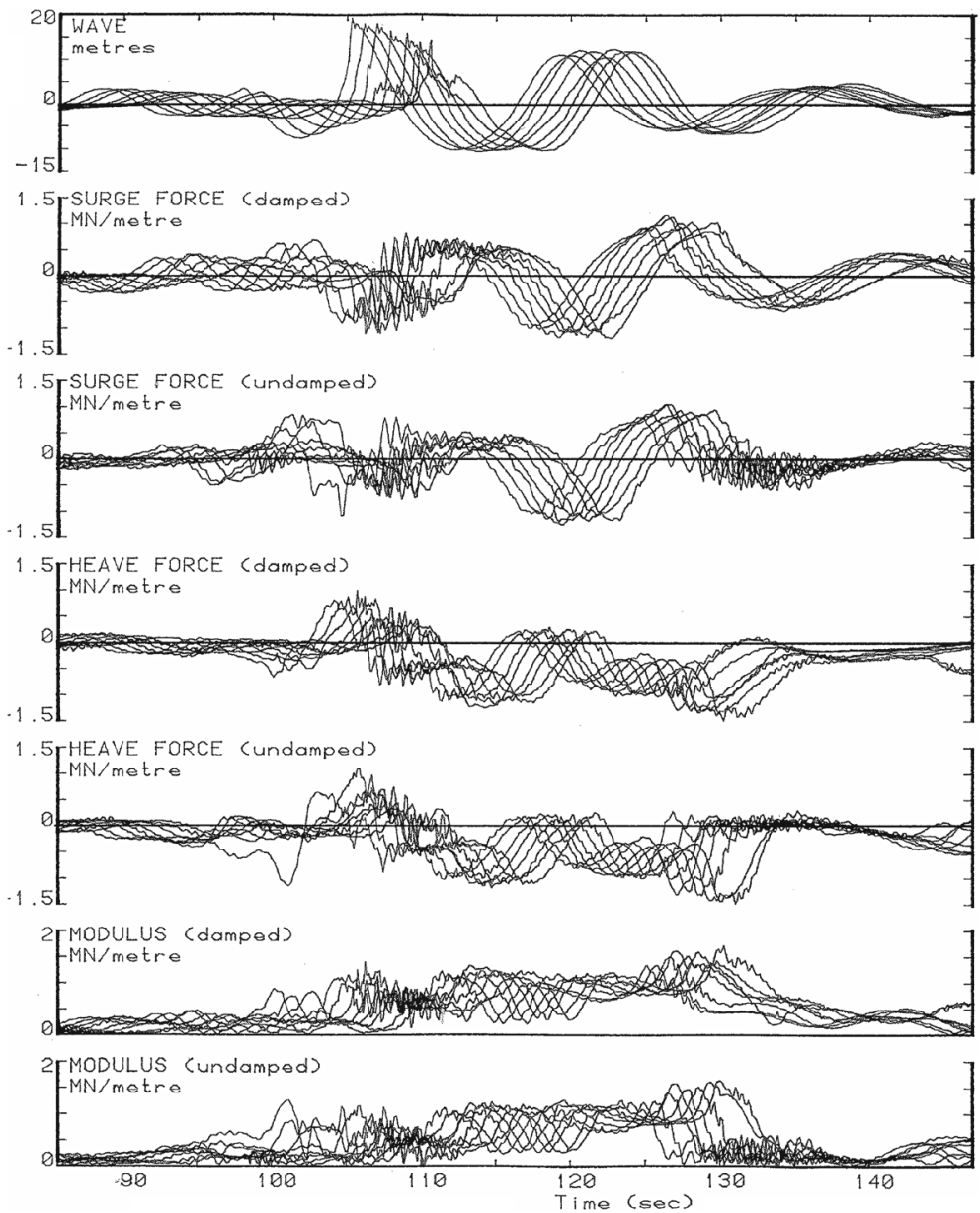

Fig. 6 The superposition of a set of time series records of the forces during a freak wave on a duck on a rigid mounting. The records are taken with the model axis at each of the vertical tick points along the water line shown in Fig. 5. Note the downward forces and the

this path does not deserve insurance but will certainly need it badly.

There were always anxieties about whether results from small models at around 1:100 scale could apply to full scale. We hired a 1:10 scale tank for a week at a cost ten times that of the material to build our narrow tank. The results were within $2 \%$ of our narrow tank ones with efficiency slightly better but, while you could lift a 1:100 scale model with one hand and make it in a day, dropping a 1:10 scale model could easily kill somebody. The 1:10 scale tank took twenty minutes instead of forty seconds to settle. Everything was far slower and more expensive but, for shapes like those of most wave devices, no more accurate.

The operators of wave tanks all have ingenious arguments to show that the size of their tank is ideal. Their effort rises in proportion to their investment. The cost of building and operating wave tanks is related to their volume. If we include the building, the initial cost turns out to be close to the cost of filling the tank with beer. larger total force at $130 \mathrm{~s}$-long after the nominal break. 'Damped' means the normal operation of the duck power takeoff which had rather little effect in such large waves. Half the testing was done with none

The forces waves exert on immersed bodies are complicated but we can gain an insight about scale from the simplest possible experiment with objects floating in still water. The two forces we could consider are the Archimedes buoyancy force and surface tension. The simplest shape we can think of or make is a cube. Let us consider cubes of different sizes made of a material with a density half that of water and with sides increasing from $1 \mathrm{~mm}$.

The surface tension of fresh water at room temperature is about $0.072 \mathrm{~N}$ per metre and will act over a length of four times the side of a cube. It will be up or down according to whether the material is wet or not. If a 1-mm cube was immersed to a depth of half its side, Archimedes would say that his buoyancy force was $4.89 \times 10^{-6} \mathrm{~N}$. A non-wetted cube with a side of $1 \mathrm{~mm}$ will have an upward surface tension force of $2.88 \times 10^{-4}$ Newton. This is nearly 60 times more than Archimedes so that 1-mm sized insects can happily walk on water with dry feet. However, the cube law is very powerful. For a $10-\mathrm{mm}$ cube, the surface tension ratio 

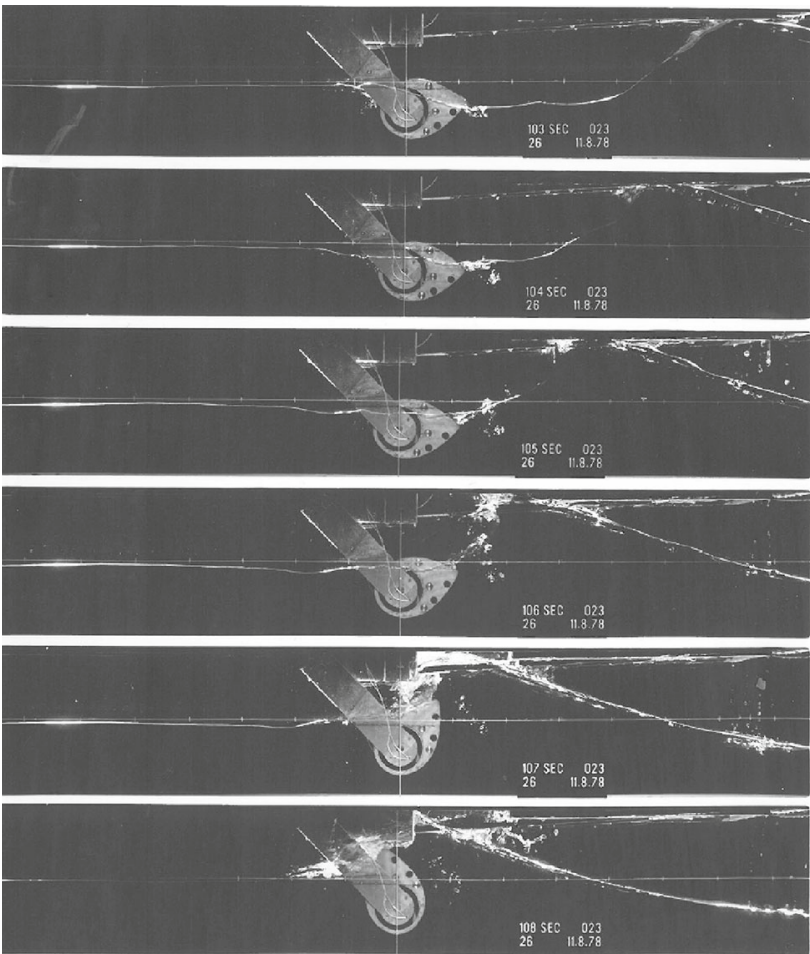

Fig. 7 Water positions during the passage of a freak wave taken at one second intervals full-scale
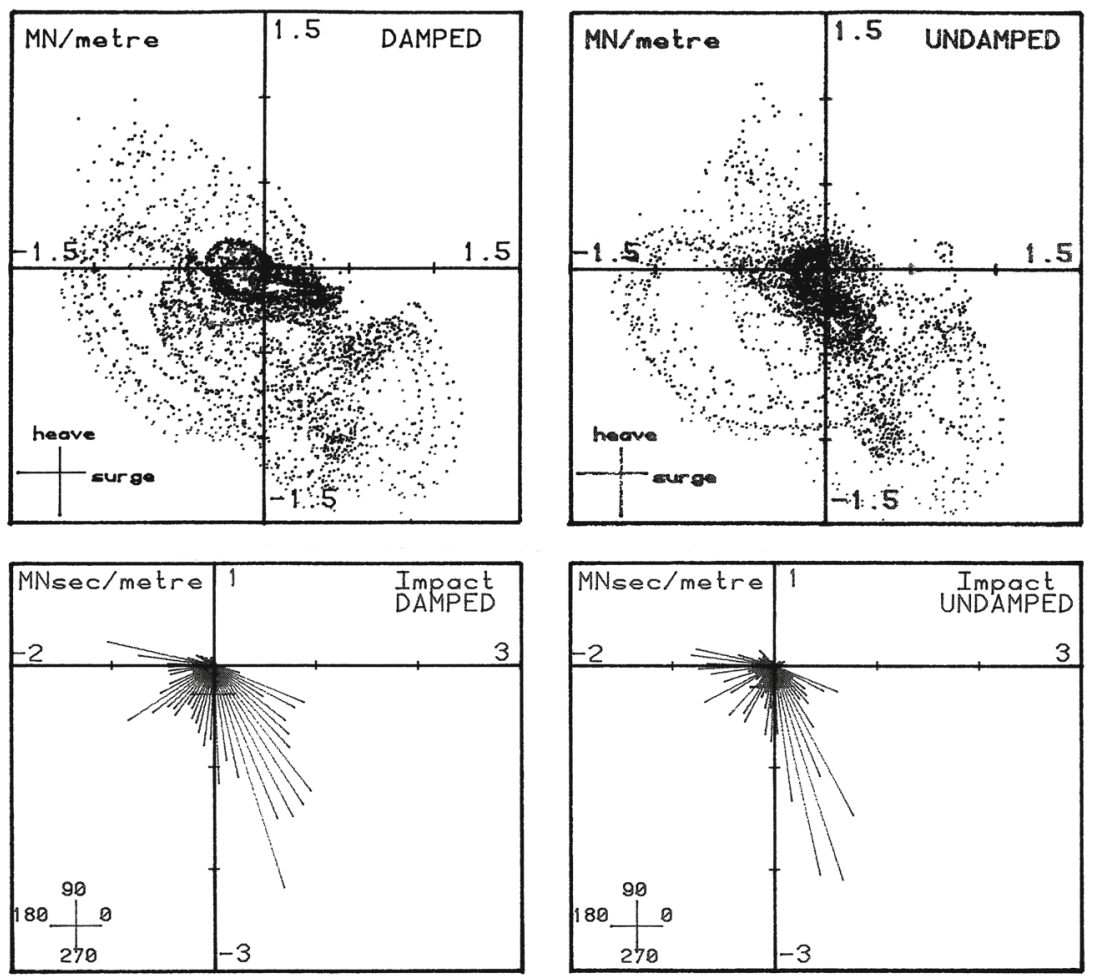

Fig. 8 Lissajous plots of the vertical heave forces plotted against surge forces. Note the low forces in upward-forward quadrant. The lower figures are force multiplied by time for each direction. Taking power makes little effect in extreme waves 
is opposing its velocity and also multiply force times velocity with regard to phase to get instantaneous power. I argue that it is a very bad mistake to try to make the model power takeoff be anything like a microscopic version of the fullscale one. Power goes up with scale to the 3.5 , so $1 \mathrm{MW}$ at full scale is only $100 \mathrm{~mW}$ at a scale of 1:100. Bearings for any model connection must have the lowest possible friction while the full-scale bearings will be the very largest available. For early lessons, we can learn a great deal from watch makers.

The mathematically simplest force would be one proportional to velocity, but this turns out to be quite difficult to implement at full scale. The constant of proportionality for the ideal device will be a damping coefficient with the same value as the hydrodynamic damping of the device driven in calm water. It may well vary with frequency, and so we want to make it easily adjustable. It will not be economic to provide the correct force for the biggest but rare waves, and so we will need an easily adjustable force limiter.

The model power takeoff should be more flexible than the full-scale one. The Edinburgh group built a controller, called porcupine, to test extreme absurdities of power conversion in regular waves. The period of the wave was split into sixteen different time slices. Either the damping force or the damping coefficient could be separately set for each slice. We found that it was possible to generate with almost no drop of efficiency (but with a nastier energy-storage problem) with generation for only half the wave period. What matters is the area and mean direction to the 'centre of gravity' of the force-velocity diagram.

The results of the work with the pitch-heave-surge rig were convincing enough to justify building a wide tank to test long-spine models. This had to be designed backwards from $£ 100,000$, the maximum amount of money which could be authorised by the programme manager, Clive Grove-Palmer, without going to a superior committee which had a member who was certain to oppose it. We got the go signal on 1 June 1977.

Meeting the cost was made possible only by the purchase of 120 scrapped printed-motors which had been stripped out of ancient IBM disk drives. Some of the armatures had been overheated and had come unglued. Opening the case to reglue them broke the magnetic path and destroyed the magnetisation of the alnico disks which energised the gap. Each of these magnets was wrapped by one and a half turns of wire leading to terminals outside the case. We calculated that it needed a current pulse of 7000 amps for one millisecond to reset the magnets but that a pulse of $10 \mathrm{~ms}$ would melt the wire. The resetting of the magnets was done by Glen Keller, but the method he used has been removed from this paper for fear of prosecution by the Health and Safety Executive. He recovered over 100 good motors, most of which were working still, forty years later.
While the tank building was being put up we built the wave-makers and drive electronics with the help of students and school leavers, many of whom are now successful engineers. Filling with water was complete on 1 January 1978. The electronics for 89 wave-makers and the drive software were debugged in two weeks and a rival wave power team began testing on 1 February 1978. We had overspent the $£ 100,000$ limit by $£ 1800$, but we had built some spare wave makers and sold them to Herriot Watt University for the exact amount of the overspend. A second tank with 60 identical wave-makers was built near Southampton, and soon both were working 24-h shifts. An even bigger one with flatteringly similar but very much bigger wave-makers was built in Trondheim. It took us 18 months to get money to build duck models to test in our wide tank, because politics had reared its ugly head. It would be painful for me to repeat the miserable account, but it can be found in evidence given to a House of Lords committee which can be downloaded from Salter (1988). Suffice it to say that, if the failure rate of marine cables for our ducks predicted by the official consultants was suffered by the cable from the UK mainland to Orkney, it would by now (2016) have failed 140 times but has not failed once.

\section{Jumping the gun}

The traditional, and sound, engineering approach for many projects has been to calculate or measure from previous projects or models, all the loads on a structure before finishing the design and then to make a series of design modifications in the light of cost calculations before arriving at the final optimised result. However, politicians and investors want to know the bottom line before making any initial investment and are in a position to enforce their wishes for early figures for the cost of electricity. This is very much like people wanting to know the winning horse before placing a bet.

Work on the full-scale design was carried out long before we knew enough about bending moments and mooring forces. We had help from the big civil engineering company Laing, who taught us lots about the advantages of posttensioned concrete in sea water. The first power takeoff was based on getting a torque reaction from a pair of gyros spinning in opposite directions. If they were allowed to process freely, they would lock a frame against which a ring-cam pump could do useful work. Two advantages were that the gyros could also be used as flywheels to store energy for tens of minutes and that everything was hermetically sealed in a super-clean vacuum. The disadvantage was that the full duck torque had to go as a radial load through high-speed gyro bearings. Robert Clerk designed some amazingly efficient hydrostatic ones with active impedances and fine clearances despite large deflections, but we could get only about half the desirable torque. 


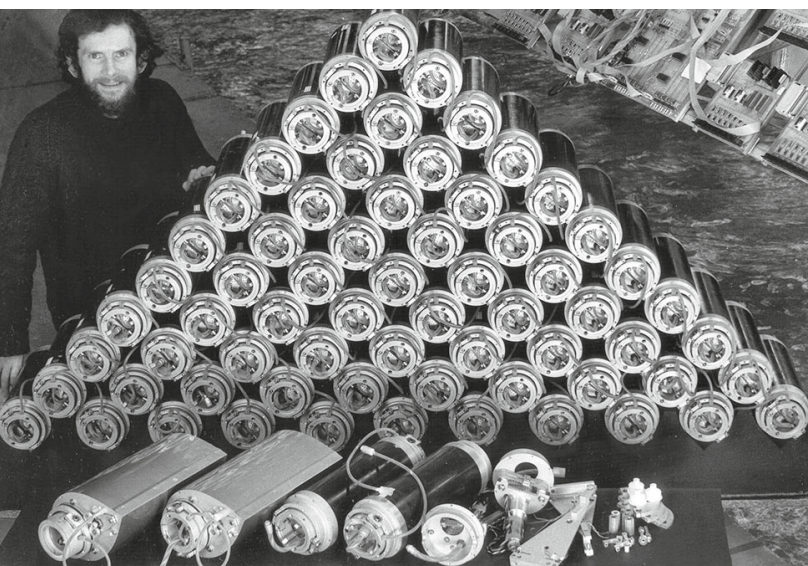

Fig. 9 David Jeffrey with the complete spine model. Beam elasticity could be varied electronically from the control bench. Two illicit generic absorbers can be seen, lower left

During the delay in getting money for a proper wide tank model, we tested bits of plastic drain pipe and learned that spanning wave crests was indeed a good way to get a stable reference. We also found that long, free-floating, low freeboard spines would move gracefully out to sea when waves began to break over them instead of ending up on the beach and that they liked to lie beam-on rather than head-on to waves.

\subsection{Long spines}

The model we did eventually get to build had electronic control of stiffness and limiting bending moment at the joints and realistic power takeoff for each duck. Figure 9 shows David Jeffrey with the set of spine joints, and Fig. 10 shows the model in the tank. However, by this time, we were told by the project officer from the Atomic Energy Authority that we were not to do any duck tests and must merely confine ourselves to 'generic spine research'.

Ducks want a mooring which allows enough movement to avoid excess stresses but does not require too much strain in electric conductors. The proposal was to use what the oil industry calls a lazy-S. A line from the seabed rises straight to a float, descends to a sinker, and then rises again to the spine connection. An increase in the mooring force will raise the sinker and lower the float. The directions of the lines and the angles at their connections will change but without much change in the tension.

The first tests in a multi-directional sea produced a horrifying result which we thought would be a complete show stopper. The spine moved with a very slow but very large amplitude in the axial direction, square to wave propagation. The inertia in that direction was very large, but the spring rate was almost zero. At full scale, the period would have been twenty minutes and the amplitude well beyond the range allowed by the lazy-S. The solution was two move

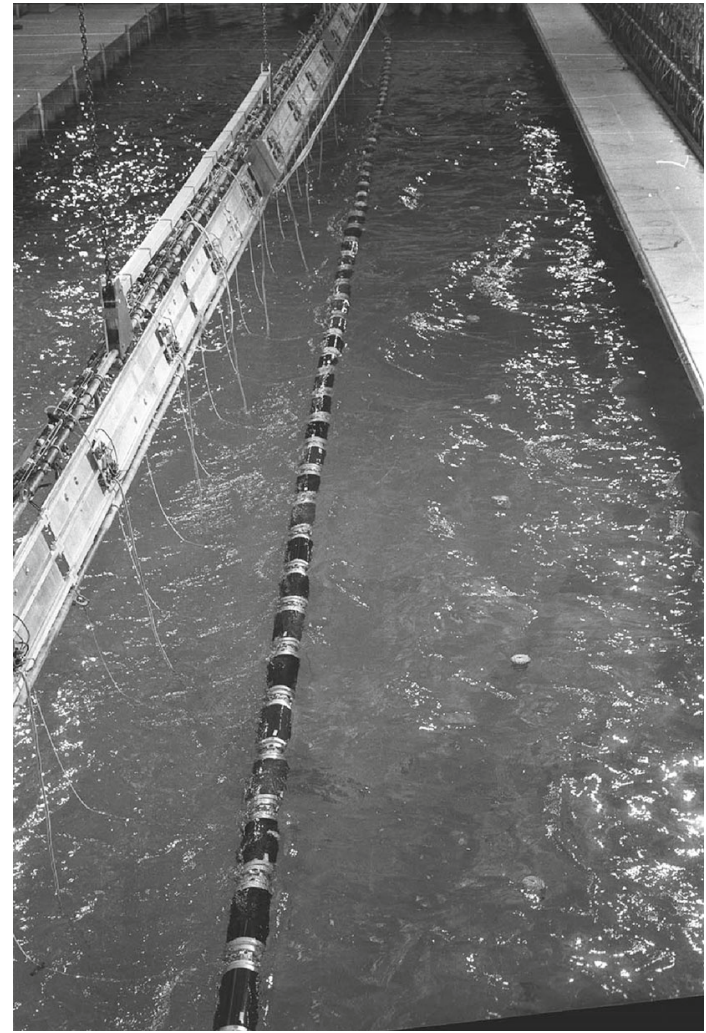

Fig. 10 The long spine model on the wide tank. The dynamics of each joint had electronic control of stiffness, damping, and yielding bending moment with measurement of bending moment and joint angle

adjacent anchor points closer together as shown to produce axial restraint, as shown in Fig. 11.

We found that bending moments were highest about half a crest length in from each end of a very long spine, rather than in the middle as would be expected for short spines. There were also some interesting results with some oblique sea states inducing very large bending moments at the downwave end. The reason was revealed when Taylor (1984) plotted results of bending moments in the same matrix format as a 'pox-plot' diagram that showed the distribution of period and angle in the 46 sea states selected for testing all UK wave devices.

In Fig. 12 upper, each sea has been represented by 75 points carrying equal energy. One coordinate of a point represents the period of the energy from zero to $20 \mathrm{~s}$. The other represents the angle from which it comes as 'hindcast' by the Institute of Oceanographic Sciences from knowledge of weather systems in the Atlantic at the time.

In Fig. 12 lower, we can see the surge and heave bending moments along the spine for a 46 joint model with joint stiffness set to $1000 \mathrm{Nm}$ per radian, model scale. The surge bending moment is always larger than the heave. The high down-wave bending moments are evident in sea states 220 , 360,366 , and 371 with their obvious cause in the corresponding pox plots. 


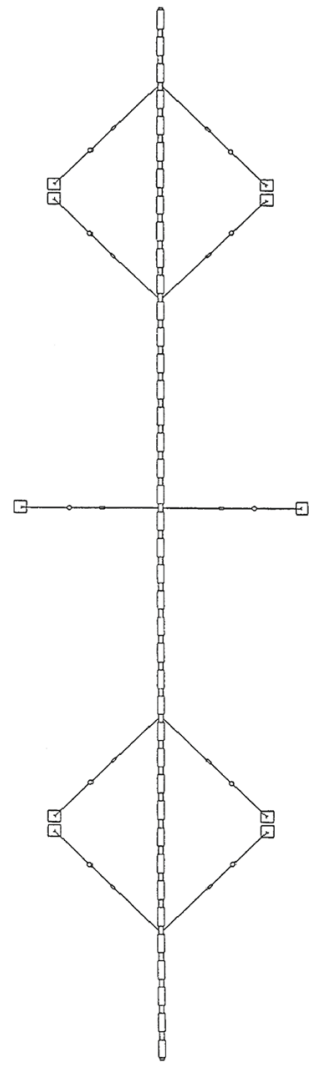

Fig. 11 A plan view of the mooring modified to remove the slow axial oscillations

Chris Retzler measured spine bending moments as a function of wave frequency and the angle between wave crest and spine with a wide variety of appendages. These included, extra buoyancy skins, square corners, fins, increased freeboard, and vertical plates. His results shown in Fig. 13 show a $\mathrm{V}$-shaped response. All the appendages increase bending moment relative to the bare spine. The largest increase was with the largest increase in freeboard. The increase occurs when the propagation velocity of the flexure wave along the spine coincides with the intersection velocity of the wave crest which causes it. As the flexure wave is a function of joint stiffness, which is under our control, it is not a cause for concern and can indeed be turned to advantage as in Pelamis. The largest credible wave at the most sensitive joint produced a deflection angle of only $4^{\circ}$. The full-scale joint angle would allow $12^{\circ}$ giving the full-scale design a factor of safety of three. After some brilliant design, the joints for Pelamis could move $40^{\circ}$.

\section{The mooring problem}

As well as the alternating wave-by-wave forces on any wave device which we wanted to resist with connections to waves of opposing phase somewhere along the spine, there is a steadier momentum force predicted by Longuet-Higgens and
Stewart (1964). This depends on the squares of the amplitudes of incident plus reflected minus transmitted waves. Clearly, we should never reflect any waves and should try to transmit all the waves above some economic limit. Transmission will occur naturally when waves break over a device, so low freeboard, exactly unlike a harbour wall, is indicated. It might also occur from deliberate spine flexure. However, if the breaking is non-linear, it can induce frequency doubling. If this happens without too much energy loss, we can get an increase of wave amplitude in the transmitted wave. This should reduce or even reverse the mooring forces which is why our plastic pipe models moved out to sea contrary to the expectation of experienced marine engineers. This levelling off and reduction had been shown in the narrow tank experiments. It greatly affects mooring design.

We built seabed anchors to measure vertical and horizontal forces from the lazy-S mooring. We could measure the spine position with very light threads wrapped round drums on the shafts of Portescap motors fitted with a tachogenerator and shaft encoder. A constant motor current would give a constant thread-tension, but we could add or subtract an additional small current to correct the very small brush friction. Today, we would use an optical Selspot system with truly zero friction. By converging directions and phases of a mixed seas, we could produce an extreme '50-year' wave that could sink a model trawler bow over stern. At full scale with no appendages, this wave would increase the tension in the lazy-S by only $2.1 \mathrm{kN}$ per metre length of spine and move the spine by only $15 \mathrm{~m}$. Measurements of the angle changes showed that we had a factor of 400 relative to cable fatigue bending tests carried out by Pirelli (McConnell 1983).

Despite the official Atomic Energy Authority ban on testing ducks, careless management and an unfortunate breakdown of internal communications meant that some ducks were in fact tested with proper moorings and a realistic power takeoff. The performance was in line with what had been predicted from the narrow tank models at the time that the long spine models had been designed, but we were not able to soften the sharp corners that give a useful increase in the larger waves. It was a surprise that quite often a fault in one duck could not be detected in the total power generation of a group of them, because the neighbours teamed up to help by absorbing reflections from the casualty. The group also produced an efficiency of $25 \%$ based on the spine length when the waves ran directly parallel to it.

\section{Parrots and monkeys}

Work had continued in the narrow tank. We found that sharp corners shed far more energy in vortex shedding than we expected. Making a small model out of toffee and sucking it shows the way. We found that the benefits of negative 

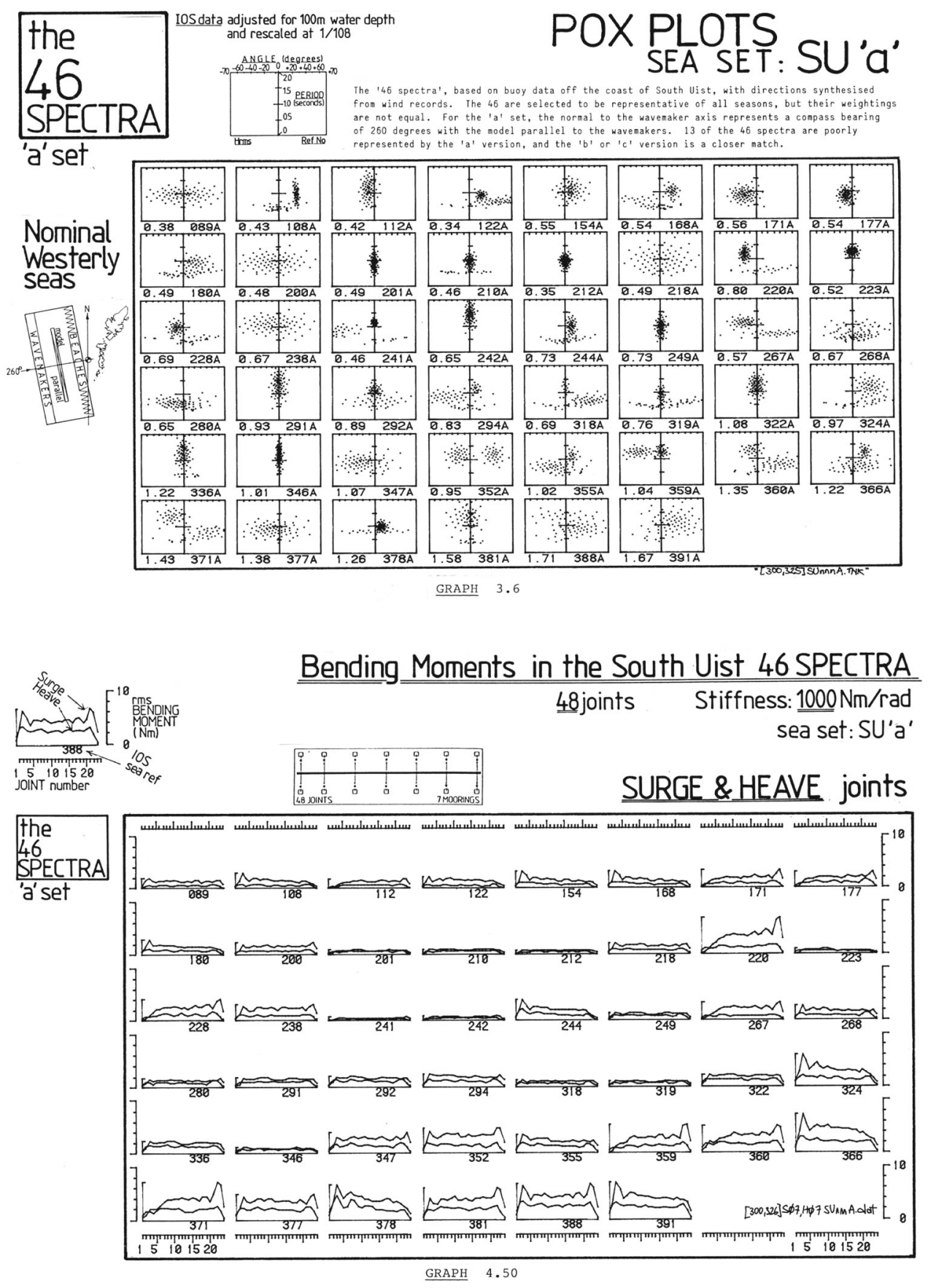

Fig. 12 The top panel shows a pox plot of directions and periods of the 46 sea states. The lower is the resulting bending moments

spring could be achieved without reverse power flow. Young and Pollock (1985) developed an iterative learning program that today would be called a neural network. It started with Jamie's best settings and then ran the same pseudo-random sea repeatedly with slight random changes to the power takeoff and mounting stiffness, keeping the good changes and abandoning the bad ones.

Overnight Henry's model could 'learn' to increase performance by as much as $20 \%$. It was clear that improvements to control strategy would never cease and that the power takeoff hardware would have to be compatible with unforeseen future improvements. Figure 14 shows his results.

However, it was by then clear that the Edinburgh strict adherence to the UK target of designing a 2000-MW power station as a first step was a serious investor repellent and certain to make ducks appear far too risky. To get adequate stability from a crest-spanning, spine needed an initial installation of at least ten units with a power rating of $60 \mathrm{MW}$. In contrast, the wind industry had started with units of a 


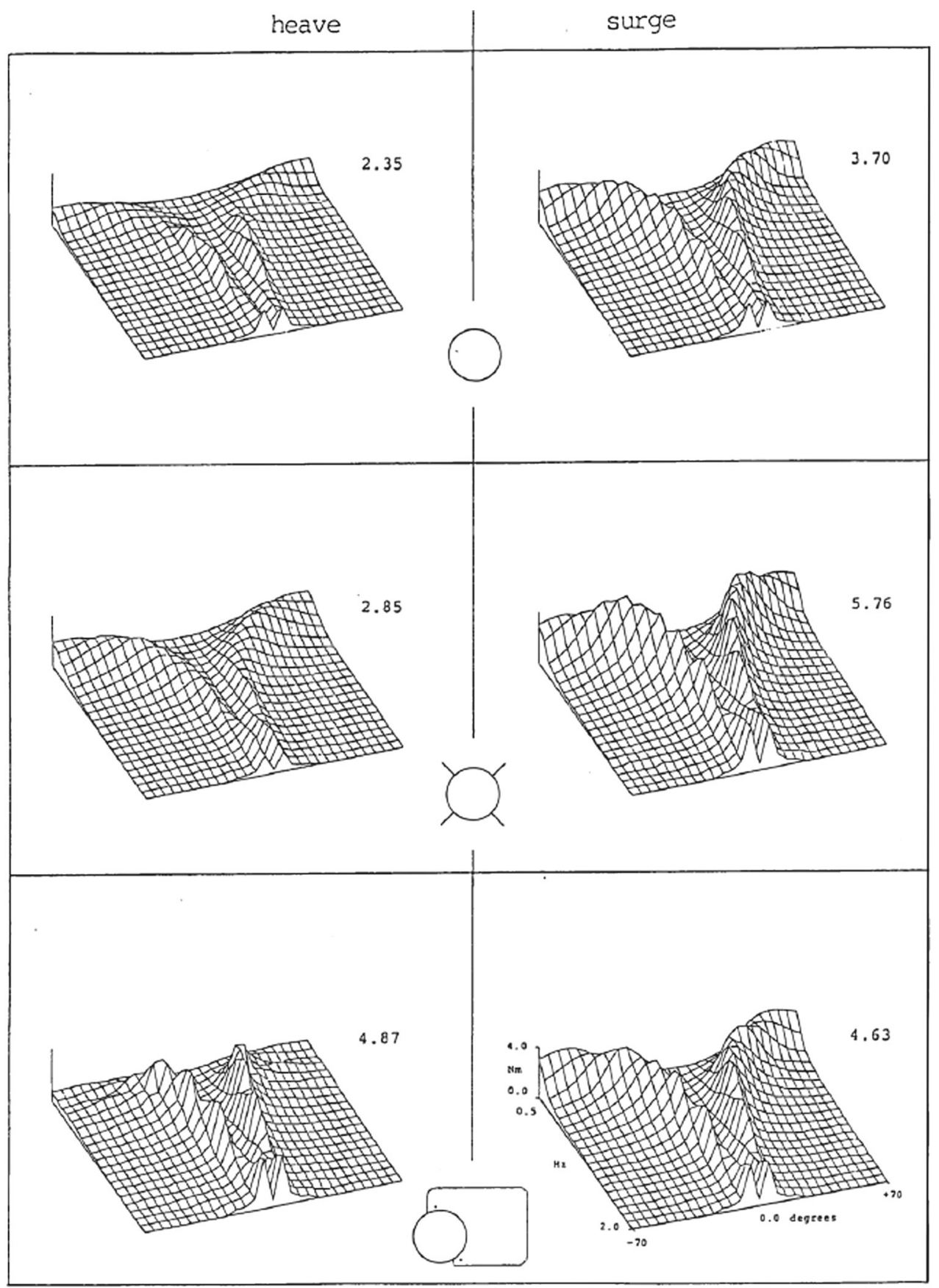

Fig. 13 Chris Retzler's V-plots showing the effect of the coincidence of the velocities flexure and wave-crest intersection

few kilowatts, and most other countries were building wave devices of a few hundred kilowatts. While Johannes Falnes had frequently urged very small devices in large numbers spaced well apart, I lived in a country with much less per capita sea front than Norway and wanted to use every millimetre to best advantage. While this might eventually be the right way, in 1983, it was as wrong as giving Bleriot the specifications for a Boeing Dreamliner. We wanted to build smaller systems of solo ducks, or even just parts of solo ducks to build confidence.
Skyner (1987) moved the pitch-heave-surge rig to the wide tank and achieved capture widths of 1.8 for most of the useful Atlantic spectrum with a 10-m diameter unit. However, for the first time, we were facing forces with nothing like spinebending to limit them and the tension-leg moorings of the solo duck showed nasty snatching if ever they went slack and then retightened. We badly needed a small system to build confidence in components even if it was nothing like a duck.

The next attempt was the Mace, Fig. 1g, a vertical, inverted pendulum meant for testing ring-cam power takeoff and 


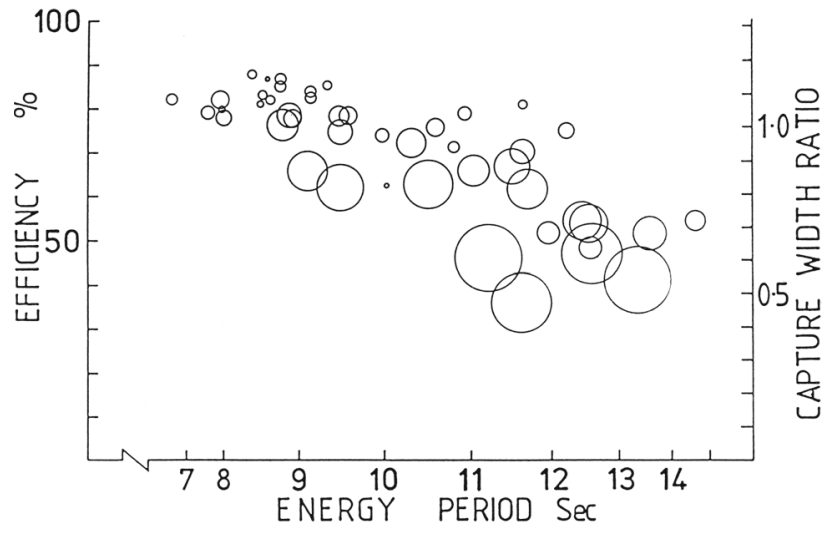

Fig. 14 Henry Young's narrow tank results for duck efficiency in the 46 sea states specified for the UK programme. Circle diameter is proportional to output power with the effects of torque and power limits showing in the largest seas. The period axis has been stretched to reflect the energy content of the Atlantic South Uist wave climate with clipping of any sea states above $100 \mathrm{~kW} / \mathrm{m}$. Harwell reported to the UK Department of Energy that 'efficiency of wave plant was typically $40 \%$, a distortion fraction of $45 / 46$ or $97.83 \%$ '

driven through tapes wound round the cam leading down to seabed attachments. It had a very wide but rather low efficiency band at much longer wave periods than any heaving buoy, a vacuum energy store in its column, extraordinary survival features and no need for end stops.

If buoys moving vertically were too stiff and flaps moving horizontally not stiff enough, it was interesting to ask if movement along a slope direction would be a happy compromise. Pizer (1994) used his own numerical prediction software to show that this indeed was so for a wide range of device shapes. My phobia about translations and end-stops in wave devices was reduced by the stroke-limiting feature of the Swedish IPS buoy Payne et al. (2006) and Falcao et al. (2011).

Chia-Po Lin built a test rig to find out how a sloped version would behave Salter and Lin (1995) and Lin (1999). He used a half cylinder to reduce rear transmission of waves, as shown in Fig. 15. He supported it on a straight slide with water-fed hydrostatic bearings and was easily able to adjust the slope of the slide. He drove it in calm water to measure the hydrodynamic coefficients and used these to draw theoretical efficiency curves for a selection of slope angles as shown in the middle graph and then confirmed them with true power generation.

The 45-degree prediction shows a capture width ratio above unity for a two-to-one range of period, so wide that we would not really need to vary the slope to suit changes in wave spectrum. The results are in agreement with experimental ones as shown the lower graph. It is clear that movement along a slope increases efficiency and widens the efficiency band in both directions but especially towards longer periods. It is not easy to make sloped slides at full scale and our attempts to make a free-floating sloped version of the IPS buoy have not so far been as good. However, it is clear that water displacement in the slope direction, as shown in the 1973 models that led to the duck, makes for good wave devices.

Conventional hydraulic pumps could apply analogue control of power flows from single sources by changing angles of a swash plate or bent-axis machine. We wanted to use digital control, and this had profound effects of the design of high pressure oil pumps and motors. We tried to design for the level of technology which would be available at the time we expected that the energy crisis would really hit, rather than for things that would be obsolete by then. Many of the ideas, such as the use of microchips to change mechanical design, seemed wild at the time and were questioned by people responsible for power generation issues. All were outside the field of the civil end heavy electrical engineers who were employed to assess our work. Accordingly, the task of assessing ducks was transferred from Rendel Palmer and Tritton to an outside consultant Gordon Senior. He subjected us to a sharper scrutiny than the civil engineers, who had missed a serious mistake we had made with the 1979 reference design. He checked calculations, quotations, and data from tank experiments. His questions and comments were a great help in improving the design.

The consultants had to consider many sorts of data. There were the heights, spectral shapes, and angular distributions of the raw wave input. There was the hydrodynamic performance of the devices. There was the conversion efficiency of the mechanism used for generating electricity, collecting it, and transmitting it ashore. There was the reliability of the overall system. There was the capital cost of building yards and of the devices and transmission cables. There was the rate of interest charged for the loans. There were charges for installing the devices and charges for maintenance. Finally, there was the ultimate life. Some of these data are well known. Some can be measured by experiment. Some have to be guessed. Some are unalterable. Some can be changed by better understanding or more intelligent design. Many can be misinterpreted through accident, malevolence, or enthusiasm. Some remain unknown. If input data are false, no amount of subsequent processing can improve the conclusion. However, it has always been necessary to decide policy with imperfect assumptions. With skill and luck, some of the mistakes cancel others. The history of official cost predictions at values of the time up to 1982 is shown in Fig. 16. On the basis of this information, the Secretary of State for Energy, Nigel Lawson, now Lord Lawson, decided to wind down the UK wave energy programme.

\section{Spectra and tuning}

Many wave developers mention the word 'tuning'. The word is used by radio engineers to describe their way to block 

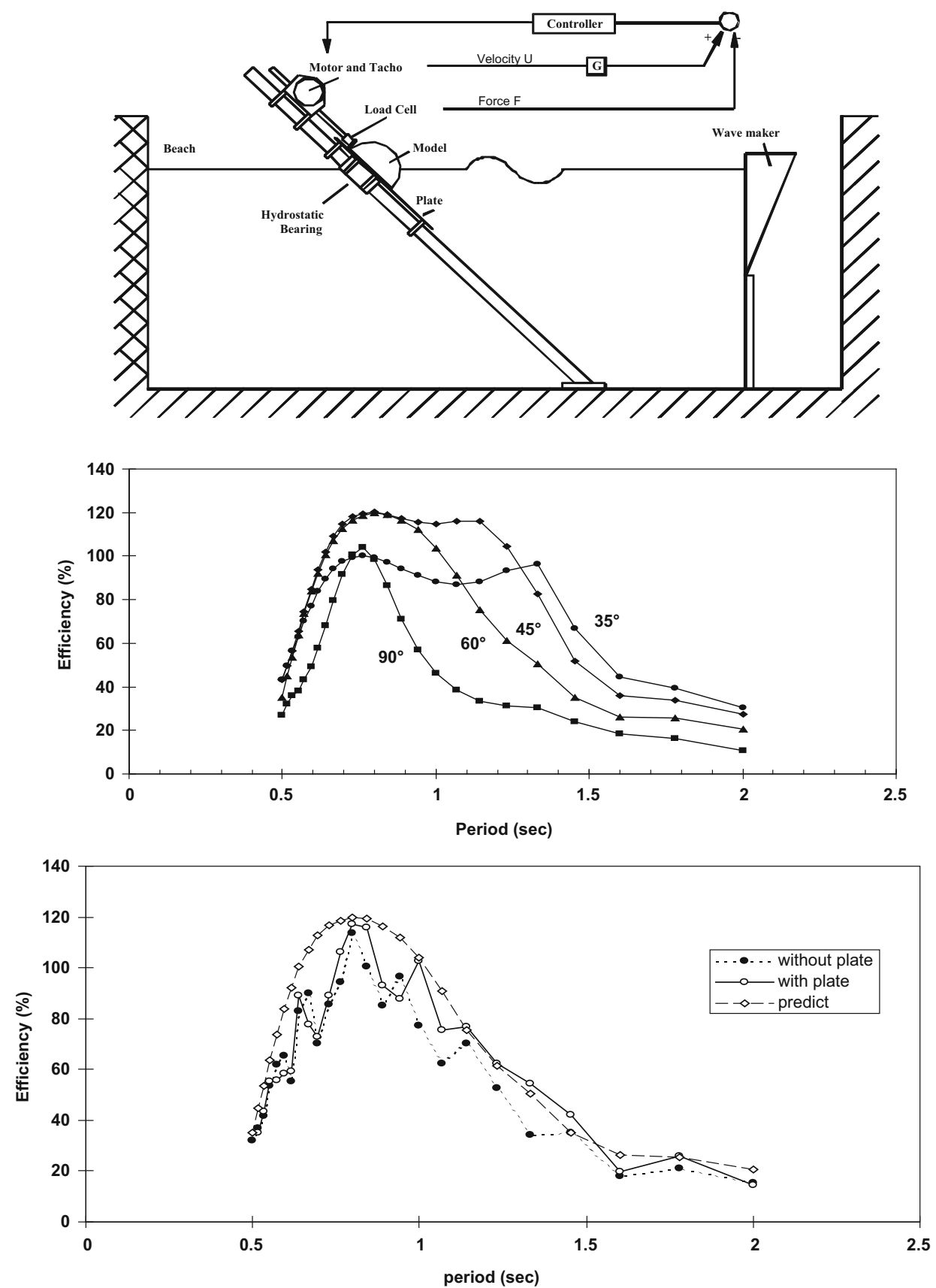

Fig. 15 Chia-Po Lin's model and results for a half cylinder moving on a fixed slope. Top model set-up. Centre efficiency from hydrodynamic coefficients. Bottom measured efficiency at $60^{\circ}$

reception of signals from unwanted transmitters. However, wave engineers want to listen to all the transmissions at the same time. We therefore want to detune the response. The perfect wave absorber would present the right value of resistance to water movement with force always in phase with velocity. However, inertia of the structure and added inertia of the water around it are inevitable. They feel a force in phase with acceleration. We should try to counter their effects by allowing water particles to move in their natural way with orbit diameter decaying exponentially with depth.
We then want to choose the right amount of spring, with force in phase with change of position and, therefore, $180^{\circ}$ out of phase with the acceleration force, for resonance in the expected wave spectra. The radio engineers would advise a low-Q resonance with resistive forces as large as possible relative to reactive ones. However, the Taylor pox-plots in Fig. 12 show that about half the sea states have more than one spectrum, so choice is not easy. I repeat, phase is the key.

Tank tests are now often done with a JONSWAP spectrum. This is based on measurements of new waves developing 


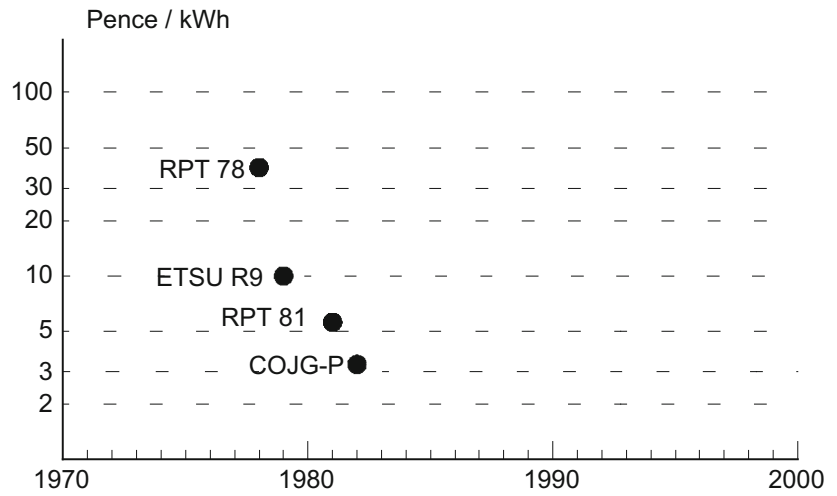

Fig. 16 Official electricity costs for spine-based ducks during the first part of the UK wave energy programme from Rendel Palmer and Tritton, the Energy Technology Support Unit and the programme manager, Clive Grove-Palmer, whose figure was based on final development

over a short fetch and is much narrower than the other mathematical descriptions of wave spectra. It will give an over optimistic prediction for highly tuned, narrow bandwidth designs when they are come to be used in the long fetches of big oceans. I advise either real spectra or at least pairs of spectra with amplitudes varied to cover the scatter diagram, at least by a factor of two.

\section{A thought experiment for future work}

Let us imagine a wide test tank with a large number of separate, narrow, dry-back wave-makers along one wall. Opposite the row of wave makers is a rigid wall which will act as a perfect reflector of all incoming waves. A single wave-maker at the centre of the row generates a wave group, which radiates out as concentric semi-circles according to the Huygens principle. Figure 17 shows the group about to arrive at the reflecting wall. The single wave-maker will have been putting power into the water that can be exactly measured from its force and velocity or torque and angular velocity. The reflections from the vertical will be like waves from the mirror image of the source behind the reflection wall and are shown in Fig. 19.
Suppose now that the rigid reflecting wall is replaced by a second bank of dry-back wave-makers which are driven, so as to produce wave fronts that are the exact inverse of the reflections and so would cancel all the reflections at every point in the tank. If energy has been put in by the first single wave-maker but is no longer anywhere in the water, it must have been absorbed by the second bank of wave makers. We could measure the amount of energy from the force and velocity signals from each of them (Fig. 18).

What is true of a short wave group from the original single wave-maker will also be true of a second wave-maker and indeed of all the wave-makers making a continuous sea state from a large number of separate wave fronts at various angles and wave lengths. We could either calculate the command signals to the second bank with a computer fed with information from the first bank or measure the forces exerted on them by the waves and set up a control loop to maintain a relationship between forces and velocities. This would allow waves from any other objects in the tank to be absorbed as well as ones from the wave-makers.

This form of force control is now common in a large fraction of the world's test tanks and gives very much greater stability for long wave tests and faster settling between tests. The optical analogy is not quite perfect. For waves approaching a wall at acute angles less than about $20^{\circ}$, the Mach stem effect splits the wave front into one part running along the wall, and a second part reflected at a steeper angle than would be predicted by classical optics. Wave absorbers can make allowance.

The absorption idea would not work if the wave-makers produced waves on both sides as does the widely popular heaving buoy which radiates a circular pattern of waves. While some of this radiation can cancel waves that a stationary buoy would have reflected, they are also sending energy to where the water would have been calm. A possible way to avoid some of this loss would be to have a line of close-packed heaving buoys placed a quarter of a wavelength in front of a reflecting cliff, so that the wasted energy is returned with the correct phase. But what is the right phase for one wave length

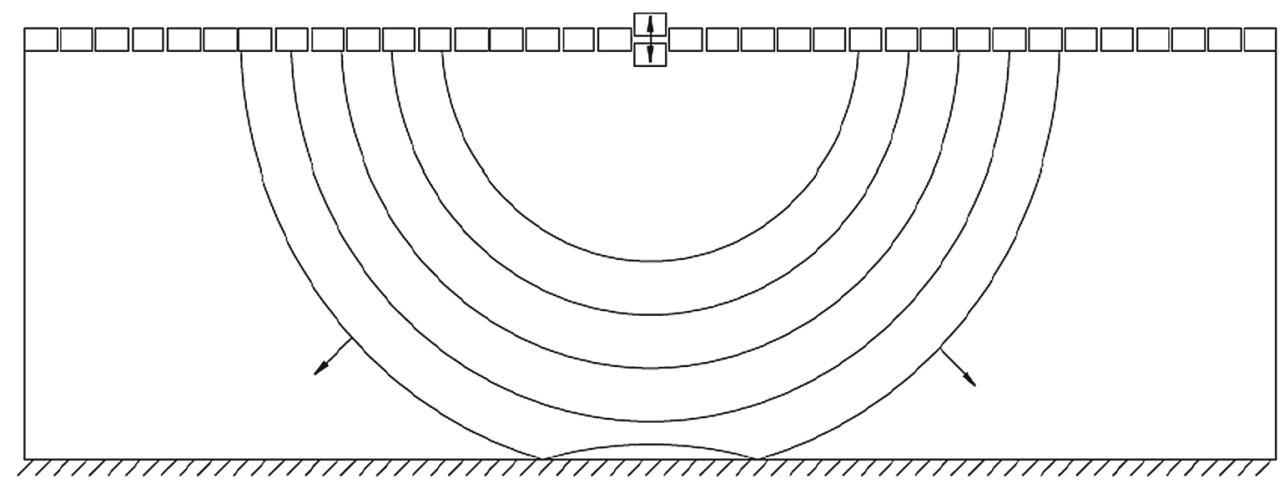

Fig. 17 A single wave-maker sending a group of circular wave fronts to a reflecting wall 


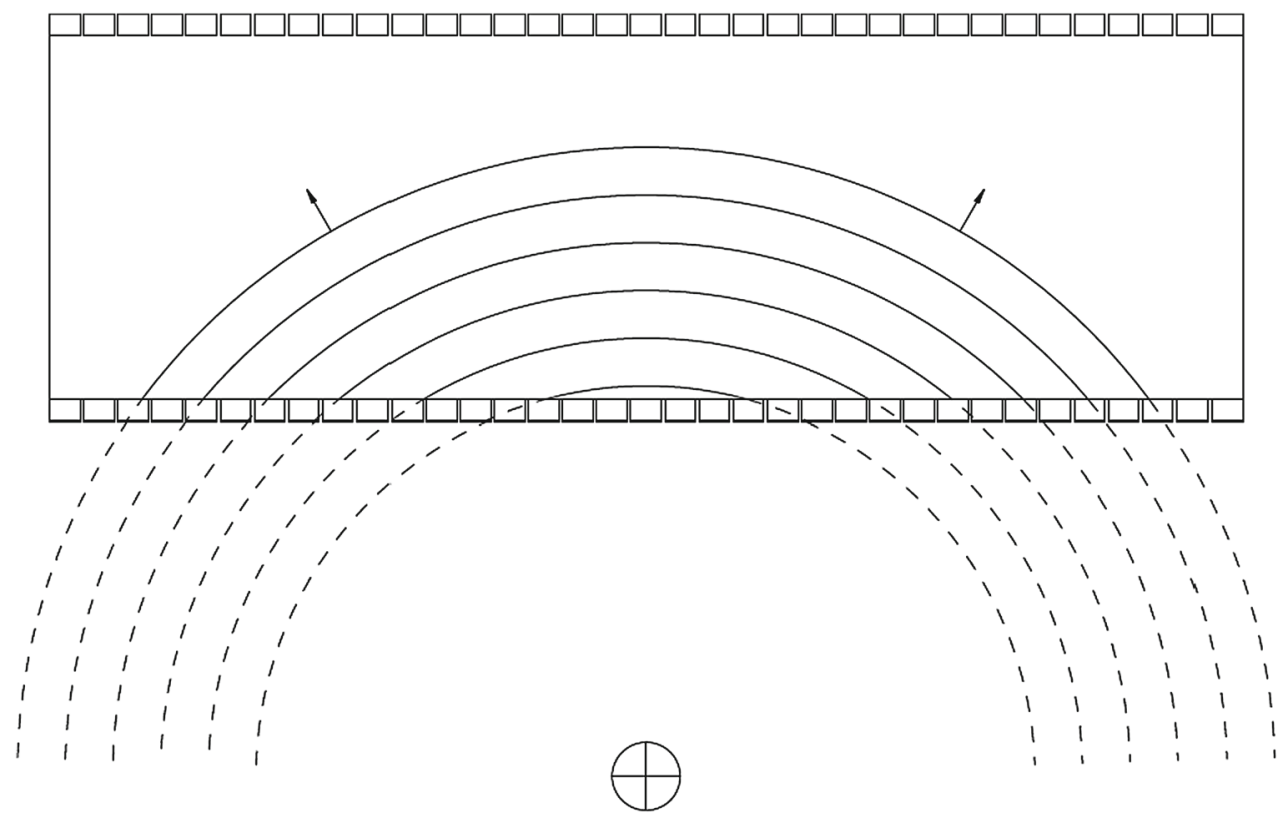

Fig. 18 The reflecting wall has been replaced by a row of dry-backed, hinged-flap wave-makers which are driven to produce the inverse of the reflection from the rigid wall. The fronts would appear to come from a point source placed at the mirror image of the single wave-maker

and amplitude will not be correct for different ones. A crest of a wave in an irregular sea is seldom the same magnitude as the next trough. The loss of energy from unwanted radiation patterns would not matter in countries with very long coastlines or at mid ocean sites with energy coming from all round. But if we want to take full advantage of the near-shore coast resource, we should try to use shapes and motions that generate or absorb waves only on one side, at least in low and moderate sea states.

There are several possibilities to reduce waves transmitted astern: air-filled bags or sliding wedges mounted on a fixed back wall and the Edinburgh duck mounted on a long spine are all obvious. A particularly efficient one is the Evans cylinder mentioned earlier. This is submerged, has a circular cross section, and moves in both heave and surge. If it moved only in heave, it would generate waves symmetrically on both sides. If it moved only in surge, the waves on each side would be antisymmetric. It follows that if it moved in both directions with a $90^{\circ}$ phase shift between heave and surge the radiated waves would combine on one side but cancel each other on the other. The result is an astonishingly efficient wave absorber with fewer moving parts than the long-spine duck system. The only snag is that a submerged, neutrally buoyant, circular cylinder has no hydrostatic spring. The spring rate needed to cancel the inertia has to be provided by the power takeoff. This can be done with very high efficiency with small models but gets much harder at full scale. Recent advances in hydraulics allow us to make high energy spring systems which lose about $5 \%$ of the energy for each transfer in or out. However, the Evans cylinder needs to put in to the spring and then take out again about five times more energy than goes into the damping system, which delivers the useful output. Future reductions in losses may be possible.

\section{Mind the gaps}

Whatever the choice of absorber I am arguing that, contrary to proposals from many developers, we should minimise gaps between them with a positive method to control the gap dimension. To start a company and raise investments a new developer must build a working prototype and the quicker the better. The choice of power levels will often be less than 1 MW far below 2 GW required by the UK Department of Energy. Attention is so focussed on the very first machine that it is easy to forget that we will be wanting thousands of them. Except, for places like Norway and the Falklands, the per capita length of high-energy sea front is quite low, only $6.15 \mathrm{~mm}$ for the UK. Isolated point absorbers are able to get more energy than is contained in their own geometrical width. However, getting the very high capture widths, which are mathematically possible, needs large movements which become non-linear. Point absorbers do not make full use of the sea front. The main importance of point absorber theory is that if close-packed devices have to be installed with moderate gaps for practical reasons, we do not need to worry so much about energy loss through gaps.

Wave energy must live alongside other uses of the sea. Mariners are used to submerged rocks and sandbanks. They greatly prefer obstructions to carry lights, bells, and radar reflectors and to be clearly marked on charts. They will pre- 

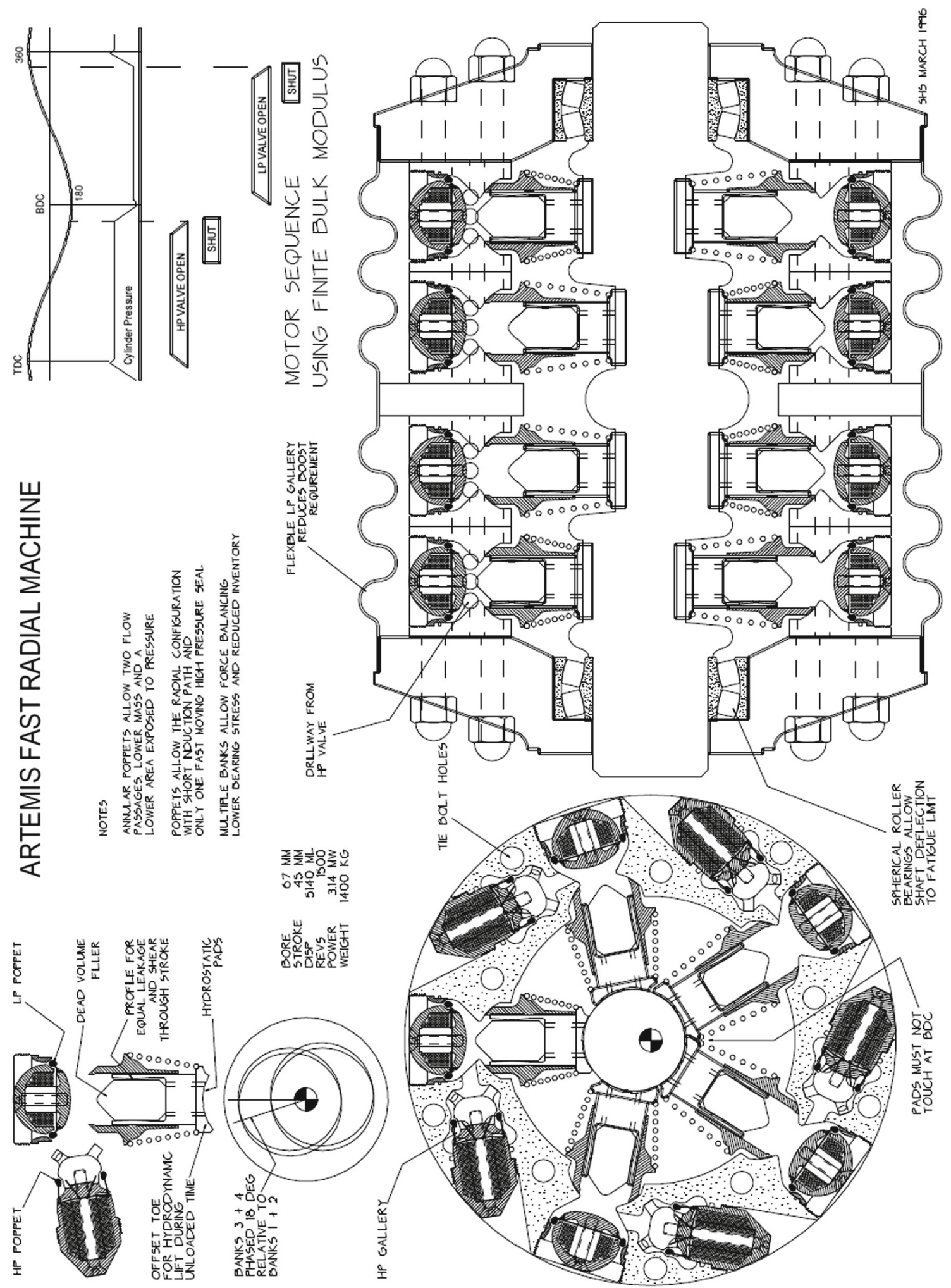

Fig. 19 An early drawing of a fast multi-bank, radial piston machine with digital poppet valve control of pumping, motoring, or idling. Later improvements have led to a commercial product 
fer only a moderate number of generously wide, blindingly obvious gaps on the great circle lines between ports to a much greater number of narrow gaps with poorly marked indications.

Owners of wave plant should not have to worry about sideto-side collisions. The crews of installation and maintenance vessels should not have to worry about being squashed in the gap. People developing isolated devices must be asked how close they will be to one another, how far will they move under the worst-case wave or fault conditions, how much gap is available for safe passage and how much energy will get through the gaps. While we will have to compete with nuclear energy, we should not attempt to mimic the collisions of neutrons and atomic nuclei.

The cost of cables has a large initial constant and is certainly not linear with rating. Large numbers of wet cable joints are expensive and possibly unreliable. Close packing of wave devices allows dry power combination up to hundreds of megawatts, levels attractive to networks especially if each element has a moderate amount of storage as close as possible to the wave input. We need to develop the technology to provide mechanical and electrical couplings with the right degrees of freedom which can quickly connected or disconnected. These couplings could use something like a highly manoeuvrable arms with and strong claws and sonar vision at the claw tips. We will need to fit such arms to maintenance vessels, so that they can make a safe connection to remove and replace devices in the middle of a row. I hope that ideas for arms and claws for the seabed attachments of the Oyster will be suitable for shapes that can offer holes in pairs of steel with shapes to guide an approaching claw.

Magnets can give contact forces a bit over half an MN per square metre on steel surfaces. The clever bit is disconnection, but this can be done by surrounding the contact area with a flat fire hose and then pumping in water. For non-ferrous materials, we can make suction pads like an octopus. It is highly desirable for the response amplitude operators of the wave plant and the maintenance vessel to be the same but one installation vessel can be shared with hundreds of megawatts of wave plant, so we can afford something quite expensive, perhaps with adjustable hydrodynamics. It is also desirable for connecting hardware to be soft, either with air bags or intelligent hydraulic arms.

A further advantage of close-packed devices is that much of the testing can be done with single units in a narrow tank. A second thought experiment involves a single real narrow tank surrounded by a large number of imaginary narrow tanks placed side by side. Each tank has a wave-maker driven with different signals to mimic the effect of directionally spread irregular seas. Lots of imaginary devices will be mounted on force-sensitive rigs either side of the real one. The difference of heave and surge forces of adjacent rigs will give the distributed shear forces that would be experienced by a long spine. Beam theory tells us that the integral of a distributed shear force pattern along a beam will give the pattern of distributed bending moments. If the beam had joints which had some means to produce that pattern of bending moments, each numerical device would think that it was part of a long array. We need to build and test only one real wet model to get the result of many.

\section{Power conversion}

The change from testing in regular waves to more realistic irregular ones with a Gaussian distribution of wave amplitudes is an unpleasant experience for wave inventors. The power signal is the square of the Gaussian distribution with frightening peaks of energy that are determined to go somewhere but are totally incompatible with electrical grids. It was clear that storing energy for about $100 \mathrm{~s}$ would make the output much more acceptable. The only way to do this and still retain intelligent power takeoff seemed to be with highpressure oil hydraulics. However, the designs then on the market were too low in power rating, too low in efficiency especially at part load and were bad at combining energy flows from multiple uncorrelated sources. We did a rigorous energy analysis of every loss mechanism and ended up with a design using digital control of displacement with electromagnetically controlled poppet valves on each chamber (Salter and Rampen 1993). It did for hydraulics what the thyristors, MOSFETS, and switching-mode control have done for electronics. It allowed us to move away from swash plates and port-faces in an axial configuration to a radial one with eight or even more separate machines on a common shaft, some motoring, some pumping, and some idling all under the control of a microcomputer costing a few euros which could latch or unlatch poppet valves at the right instants. Figure 19 shows an early design. Each chamber can be controlled to pump or motor or idle with an option to change the operating mode of each chamber twice a shaft rotation.

There is now a growing need for flexible control and high part-load efficiency in vehicle transmissions and suspensions, and it turned out to be possible to fund development by work on machines for the motor industry. This development has been carried out by Artemis Intelligent Power (2016). They measured the fuel consumption of a standard BMW 5 series car over a set of defined drive patterns at the Millbrook Vehicle Testing Facility. They replaced the standard transmission with a digital hydraulic one which included an 11-L gas accumulator for regenerative braking. They then repeated the same driving patterns. High-speed motorway fuel consumption was the same, but the standard urban fuel consumption was less than half. All the vehicle power management was done by the transmission, and the engine could run at the sweet spot of the power curve, so that the carbon 
release might be even better than the fuel reduction. The system should be particularly suitable for buses and delivery vehicles which make frequent stops and starts.

There has also been work on ring cam pumps for absorbing the very high torques at low speeds needed for wind turbines (Salter and Rea 1984) wave energy (Salter et al. 2002) and tidal stream generators (Salter 2012). Mitsubishi Vestas have replaced conventional gearing of for their Sea Angel turbine. The first prototype has been built on land at Hunterston near Glasgow. The rotor diameter of $167 \mathrm{~m}$ made it the largest in the world for several weeks. The digital hydraulics allows the combination of true synchronous grid-locked generation with exact tip-speed ratio but with a much lower weight than conventional gears. Short grid dropouts can be tolerated because of short-term storage. I would like to make all the mistakes (there will be lots on such a new technology) on land before anything goes to sea.

A duplex ring cam outside the full spine diameter with the force reaction through the thickness of the cam rather than round the circumference gives an amazingly light power take off with lots of parallel redundancy. If a duplex cam is good, a quad one would be even better. This is proposed for a $200-$ MW tidal stream generator. There is a scarcity of bearings that size, but it would be regarded as very small for a railway. Short sections of cam lobes would be pulled together like beads on a necklace. A likely roller force is $100 \mathrm{kN}$ moving through a stroke of $100 \mathrm{~mm}$ giving $10 \mathrm{~kJ}$ per stroke or 40 $\mathrm{kJ}$ for one operation of four rollers on a quad cam. Readers are invited to work out how many cam lobes can fit in the circumference of the cam, then to multiply this by the number of sets of pumping modules, and then to multiply this by 40 $\mathrm{kJ}$ to get the work done in one cam revolution. I want to build complete confidence in digital hydraulics in wind and tidal stream before trying anything under water driven by waves.

\subsection{And now for something completely different}

While the new digital hydraulics was being developed, it seemed interesting to investigate a device that would inherently give the ideal torque proportional to velocity but deliver an output which in some places could be even more valuable than energy. The result was a desalination device using vapour compression rather than the normal reverse osmosis (Salter 1985; Salter et al. 2007; Cruz and Salter 2006). Figure 20 shows the arrangement. A solo duck is half filled with water. A vertical partition reaches down just past the duck axis. The inertia of the water makes it tend to stay fixed like a pendulum. Movements of the duck will vary the volumes either side of the partition, so that they become enormous double-acting pumps but with no machined parts, sliding contacts or seals. The pump chambers are full of steam, and the movements suck and then compress it from and then to opposite sides of a large heat transfer surface contained in the partition. The result is two or three thousand cubic metres of pharmaceutically pure water a day in a tropical trade wind wave climate. A cross-sectional view showing internal details is shown in Fig. 21. Figure 21 shows a 1/30 scale model with an offset axis of rotation under test pumping air through a blanket instead of steam.

Whales and elephants do not need fur coats or wet suits, because objects of that size and shape lose heat very slowly. With a metre of foam concrete for thermal insulation, the desalination system will cool at only $4{ }^{\circ} \mathrm{C}$ per month. A more serious problem is that vapour compression can produce a water purity of 0.5 parts per million of dissolved solids. It will be necessary to add quantities of trace minerals, such as iodine and selenium, if it is to be used for drinking.

A major concern was the need to raise cold sea water to boiling point and then recover heat from the fresh water and the double-strength brine. Desiree Helenschmidt built a small section of the zigzag heat exchanger design shown at the top left corner of Fig. 20. She put it in a test tank, removed the beach, and drove the wave-maker to produce a standing wave with a node at the heat exchanger model. There was one sheet of aluminium between two sheets of polycarbonate with an airspace to two more sheets to give the function of double glazing.

The unequal resistances of the zigzag gave an effective distributed pumping effect which should remove much of the pressure-related stress. A source of heat was provided by the copper strips of a sheet of Veroboard used for prototype electronic circuits. With 80 volts at $50 \mathrm{~Hz}$ across adjacent copper strips, the heater drew 10 amps, putting $8 \mathrm{~kW}$ per square metre into the water. The only available temperature sensors had a resolution of $0.1{ }^{\circ} \mathrm{C}$. The temperature increase was only just detectable, so it was possible to say that, if this was the temperature rise, we could claim a heat transfer coefficient of $80 \mathrm{~kW}$ per square-metre Kelvin, way above the performance of flat-plate heat-exchangers, because the alternating flows. With all the heat from internal fluid movements in full size plant tending to raise the temperature, we have to be careful not to overheat.

The main application will be in places with severe water problems which usually do not have such large waves as the Scottish Atlantic climate. However, this is the first Edinburgh device to have a stiff mooring, and therefore, we are extremely concerned about peak loads. One possible approach is to allow the hull or legs to fill with water if severe weather is expected and lower the system below wave action. Many sites have sandy sea beds, and it may be possible to use a combination of water jetting to sink a tripod anchor into the sand and then suction to consolidate it. This would mean that deployment and recovery could be done from light inflatable work boats with water pumps and air compressors but no heavy lifting gear. 


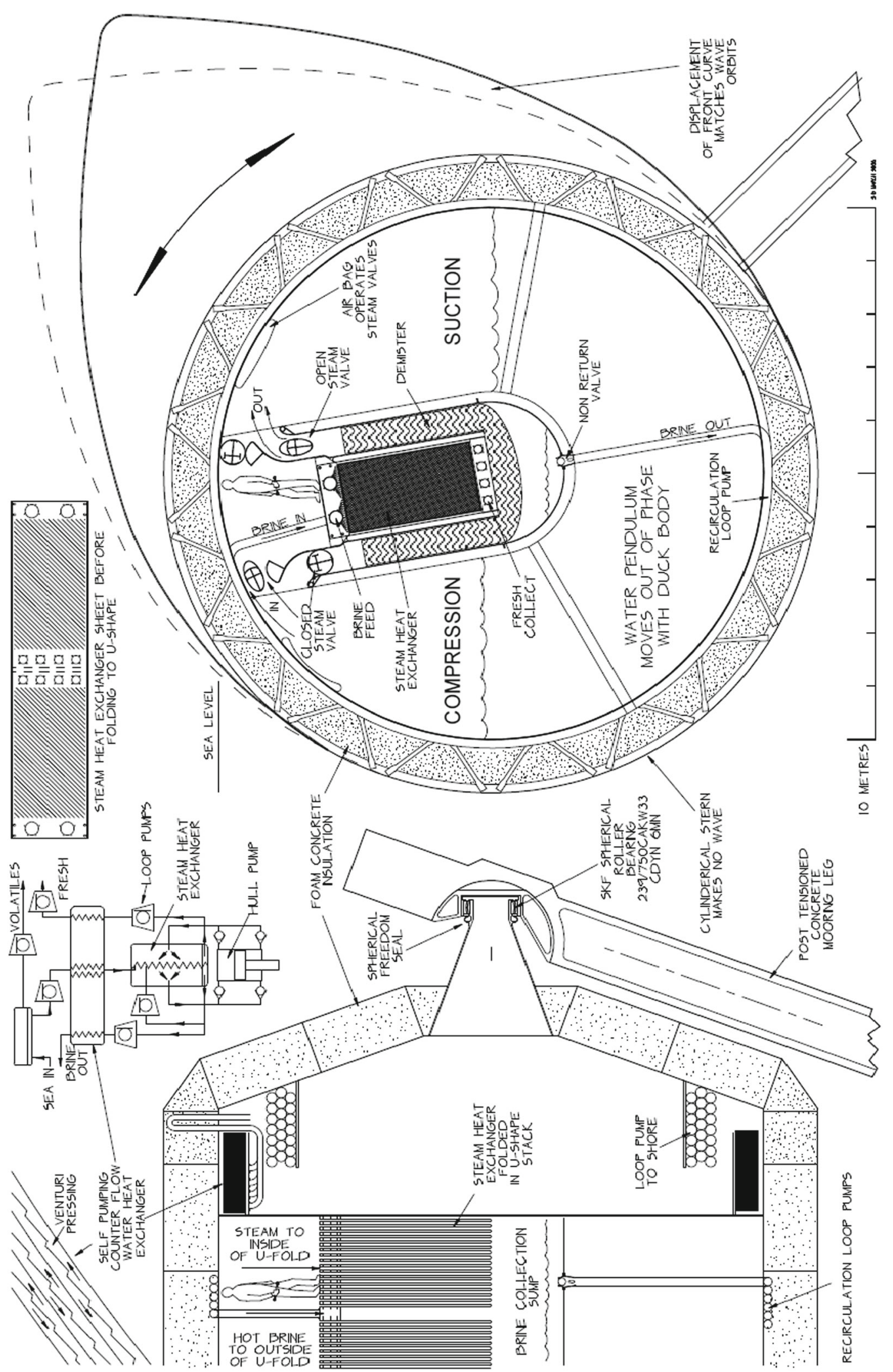

Fig. 20 Sections through the desalinating unit. People would not be present during operation 


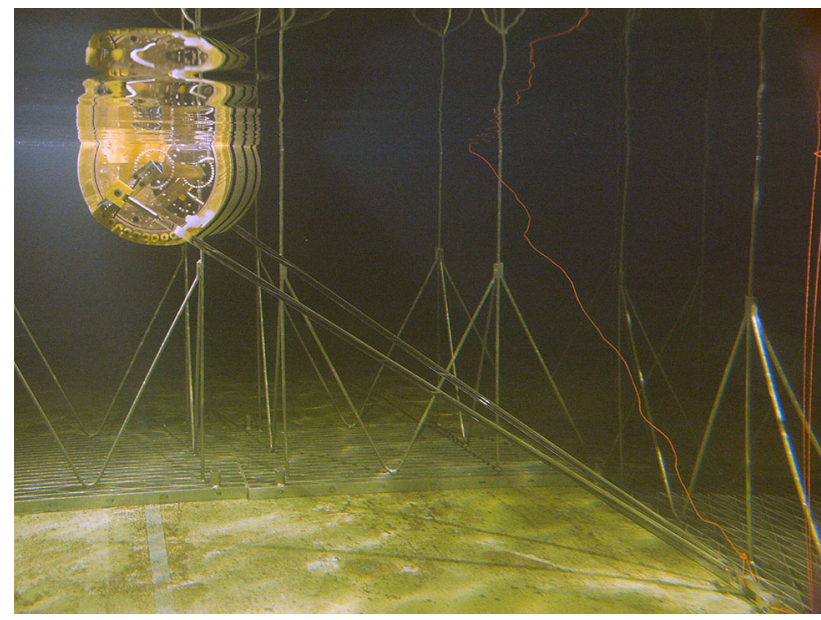

Fig. 21 A fish eye view of a 1/30 scale offset cylinder version of the desalination system, less efficient but cheaper than a complete duck. The mooring will be a V-pair of post-tensioned concrete tubes with adjustable buoyancy going to a single-point attachment at the seabed. The structures behind the Vee legs are work platforms for use in the tank

Tests by Maja Person on a single leg made from 50-mm drain pipe with mains water pressure for embedding the leg in a water butt full of sand worked quite well. Testing at the top of an 80-m high building allowed the suction to be provided by a siphon. We do not yet know about long-term build-up of sediment to consolidate the sand above the legs.

A second departure from using waves for things other electricity generation followed hurricane Katrina. The probability severity of hurricanes and tropical storms rises sharply if sea surfaces are above $26.5^{\circ} \mathrm{C}$ (Whitney and Hobgood 1997). We may be able to pump warm surface water down to mix with colder water at the thermocline (Salter 2009). This will have a higher concentration of nutrients than surface water. The mixture at some intermediate temperature will rise until it meets water of the same density and then spread sideways. If there is enough light at that level the extra nutrients will increase the growth of phytoplankton which are the start of the marine food chain. While most of the world's oceans are wet deserts, the pumping would allow permanent la Nina events with more fish.

Figure 22 shows one way that the pumping could be done. The top of the structure, called a wave sink, is a ring about $100 \mathrm{~m}$ in diameter made from used tyres lashed together containing buoyancy material, foamed concrete if it can be made impermeable. Below this is a wall of non-return valves made from extrusions of chlorinated rubber. Below this is a second ring of used tyres filled with heavier material. The rings are cross-braced with spokes. Waves can move water inwards, but the only way out is downwards through a tapered plastic tube. Mooring seem impossible, but if we can control the direction of water release, we may be able to let wave sinks drift freely round the gyres.

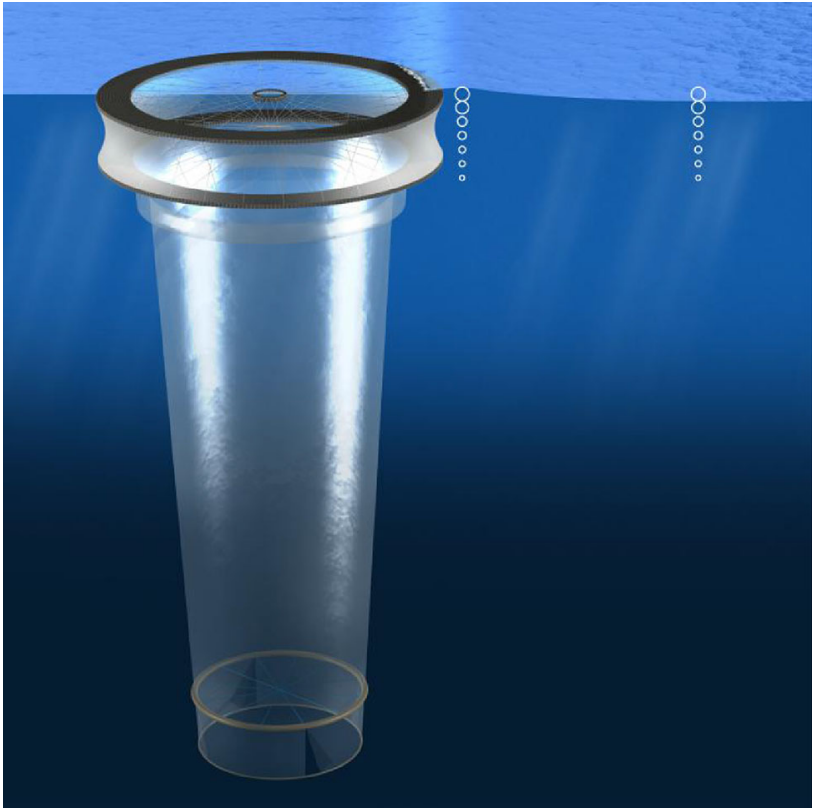

Fig. 22 The wave sink can pump warm surface water down to the thermocline to reduce hurricane severity, bring up nutrients to increase fish production and reduce marine hypoxia. (C) John MacNeill

Video of a model under test can be downloaded from a drop box (Skaf 2012). If you wait a while you will see a black bin-bag emerging below the model. This is about $1 / 100$ scale. At full scale, the flow would be about $1000 \mathrm{~m}^{3} / \mathrm{s}$. Wave crests reaching the far side if the ring will be reflected by close valves, but more water will be sucked in by the troughs. If the valve wall depth is $17 \mathrm{~m}$ the flow will be about $5 \mathrm{~m}^{3} \mathrm{~s}^{-1}$ $\mathrm{m}^{-1}$ diameter of ring per metre amplitude of wave, almost independent of wave period.

\section{Rotations translations}

It is much easier to think about translating motions than rotating ones, because the end result of a sequence of translations does not depend on their order. However, there are four practical aspects of rotations, which make them more attractive for wave energy.

The first is that rotating mechanisms do not require end stops. Well-designed wave devices driven near resonance but with no power takeoff can move through distances much greater than wave heights. I know of one case where the ratio for a small model was 13 . There can be many reasons unconnected with the device itself, such as a grid failure on land, which prevent power being removed. The amounts of kinetic energy which would have to be absorbed is large but the time or distance for absorbing it can be small.

Second, it is much harder to seal a translating mechanism than a rotating one and reliable rotating seals are already difficult enough. 
The third advantage, particularly relevant to direct electrical generation, is that all of the parts of a rotating generator can be in action all the time while, in a linear generator, only coils close to magnets can do anything useful. I conclude that rotating mechanisms are preferable but rotations about a distant axis can give a reasonable approximation to a translation.

\section{Bearings}

Many machines can be described as interesting bearings separated by boring frames. Tribologists claim that very large benefits can be achieved with very low costs. It could also be argued that very expensive results follow trivial mistakes. What wave energy needs is bearings which can take very high forces, with zero friction, infinite life, tolerance of bad geometry, and even exposure to salt water full of abrasive sand. The only good news is that velocities are usually quite low and there is plenty of coolant available.

A useful quick design rule for steel structures, at least in the dry, is that if the working strains are less than one part in a thousand your design is too heavy and if they are greater than one in a thousand you have to worry about fatigue. This means that the deflections of many designs of wave energy plant are far more than allowed for many types of bearings. However, bearings with spherical degrees of freedom are available.

The rolling bearing manufacturers have jointly agreed to specify the capability of their products as dynamic load rating. This is the steady unidirectional force which will produce a just-detectable indication of failure with a probability of 0.1 after one million complete rotations. Wave power devices do not have unidirectional loads and the loads. They hardly ever make complete rotations. Loads are the most variable one could ever imagine. One million is not a very big number for many machines; an induction motor will do that number in just over $11 \mathrm{~h}$. A typical wave power device would take about 4 months if wave conditions were steady. The bearing catalogues give several application factors and equations for other numbers of rotations. Subject to some absolute limits, halving the load will increase life by a factor of 10 .

In normal economic conditions and at the start of a project, most accountants will say that there is no financial reason to make the design life be more than 25 years or nearly $10^{8}$ repetitions of an 8-s wave. Failure rates are initially linear with time. The acceptable figure for failure rate will depend on maintenance costs and a probability of 0.1 is unlikely to be exactly optimal. After 24 years, the accountants would be delighted to have a longer life but will not accept responsibility for previously forcing a shorter one. The bearing manufactures also say that the great majority of bearing failures are caused by seals or poor installation.

We could take the scatter diagram for a potential wave site and generate a probability histogram of the bearing forces.
We could then use the equations of the bearing manufacturer to calculate what fraction of the life used by each wave in the hope that the suggested application factors will apply to wave energy. But, as well as the life equation and correction factors, some bearing manufacturers will now give an 'infinite' fatigue life. For large spherical roller bearings, which have the tolerance of geometrical misalignment so desirable for wave applications, the fatigue loads are about $15 \%$ of the $10 \%$ in a million cycle dynamic load rating. We can calculate a 'pressure' by dividing the fatigue life by the projected area of a bearing. A graph of such pressures of the larger bearings in the catalogue of a well-known Swedish bearing manufacturer shows very little scatter ranging from 35 to 45 bar. It might be sensible to skip all the algebra and uncertain application factors, design round the fatigue life values and put the design effort saved into getting really good seals. I expect that changing bearings in most designs will be very expensive, so there is a strong incentive to go for 'infinite' life, or at least getting to within a few percent.

The biggest spherical bearings look good for the extreme loads of the desalination duck, and it would be difficult to improve on the designs of a company which has been inventing new bearing technology for more than a hundred years. However, a possible problem may arise from a large number of loadings on a very small number of rollers with angular motions smaller that the angle between them. The small fretting movements may wipe away grease from the small contact area.

If this is a problem, then a possible alternative is the use of hydrostatic bearing technology. One side of the bearing has pockets into which a fluid is pumped through some form of flow restrictor. It flows out of the pocket through a fine clearance which is also acting as a restrictor. The pocket pressure will be some fraction of the supply pressure depending on the flow resistances like a potential divider in electrical engineering. If the load increases the exit gap will close and the pocket pressure will rise to withstand the increase. The nominal pocket pressure will typically be about two thirds of the supply. With intelligent flow restrictors, the pocket pressure can swing through quite a large fraction of the supply pressure with never any solid-to-solid contact. The bearing should last for as long as it is fed with clean oil but high-speed ones will fail in a few milliseconds after the supply stops. We have to pay for the pump and the energy it uses. In wave power devices using hydraulic rams, for examples, for controlling spine joints, the wave force produces an oil pressure which can be used to drive a hydrostatic bearing and, therefore, will always have the correct drive for widely varying loads.

We also have to pay for the energy wasted in viscous shear at the bearing lands around the pockets. The equations for leakage and shear are well known, but the energy consumptions go in opposite directions, so the designer is choosing values for clearance, land area, and viscosity to get some 
balance between the two for the expected speeds and loads. We can use hydrostatic pads for spherical, conical, cylindrical, and flat geometries. We now can buy pumps, hoses, and hydraulic fittings for pressures up to 400 bar, and so it looks as though hydrostatic bearings should be even better than rolling ones for wave applications provided that we can retain the desired clearances. However, there are several big howevers as follows:

- The ideal clearances are very fine, sometimes less than 10 microns and can easily be smaller than the elastic distortions of the material around the bearing.

- A single pad can tilt to make a solid contact at one corner, so groups of pads have to obey the rules of kinematic location.

- The viscosity of the working fluid is a function of temperature and there can be quite large changes with uncertainty about heat transfer through parts of the bearing to the outside and the thermal expansion of the bearing parts.

- We have to collect the exit flow and dreadful things will happen if any oil leaks into the sea.

- We have to keep the oil cleaner than the closest-ever clearances.

- We may have to park wave plant when there is no pressure supply.

While we can buy rolling bearings and expect them to work out of the box, most hydrostatic bearings still have to be special designs developed for each particular application. A possible step for the velocities which are above the very slow ones of high-load plain-bearing velocities is to supply plain bearings with oil taking nearly but not quite all the bearing load leaving a moderate fraction to be taken by the plain bearing surfaces.

When fully hydrostatic bearings are working, their requirement for high-quality lubricants is less than for hydrodynamic and plain ones. It is the non-working condition that makes demands on tribology. If suitable choices for the bearing parts allow us to relax the requirement for lubricity, we may be able to reduce the leakage problem by using water soluble, edible fluids, such as glycerine-water mixtures. The mixing ratio can give a very wide range of viscosity adjustments.

Another possible solution to avoid the leakage problem completely is to use filtered sea water as a hydrostatic fluid despite its rather low viscosity. Reverse osmosis membranes last much better if they are fed clean water. There is a brisk market for filters to do this. A group of filters can sequentially back-flush each of the group in turn with a change-over every ten minutes or so. The original filter market was for removing $30-\mathrm{nm}$ polio viruses from drinking water and so is far smaller than any hydrostatic bearing clearance.
An interesting bearing for the duck was developed by Anderson (1987). Peak wave forces on ducks in big waves are about $1 \mathrm{MN}$ per metre width. But if this is evenly shared over a metre width of a $12-\mathrm{m}$ diameter spine the pressure is only $0.083 \mathrm{MPa}$ - in expanded polystyrene country. The bearing idea is copied from synovial lubrication which can work well in human hip joints for sixty years, or considerably more if people take glucosamine sulphate.

The bearing is made as bed of springy rubber 'concertinas' filled with sea water. Axial length is chosen to suit the roundness tolerance of spine and duck, perhaps $200 \mathrm{~mm}$. They are mounted on a flexible carpet with holes which could allow water to flow in to a gap of a few millimetres. The shape of the holes makes it slightly easier to move water into the concertina than out. The projected area of the concertinas is lower than the total area between the duck and the spine and so the wave force would produce a pressure which was higher. Successful operation depends on how long it would take to empty the concertinas with flow to the far side of the bearing or its ends. Calculations showed that it would be several minutes, far longer than the time for the forces to reverse, even very long period swell. The alternating forces which cause so much misery for energy quality would be turned to advantage.

The only problem is that the bearing would not work in calm water. This could be solved with lines of ferrite magnets on the carpets facing others embedded like cat's eyes in tarmac on the spine. The cheapest ferrite magnets are made from blast-furnace slag and cost about the same as their weight in steel. We built a 1-m diameter, vertical-axis thrust-bearing which could take the weight of a student. His inertia could keep him spinning with apparently no reduction of speed for three minutes.

\section{Seabed operations}

New technologies raise demands for new tools and wave energy is no exception. We may need to do cosmetic surgery on unwanted rock outcrops. We may want to cut cones, cable trenches or prismatic shapes in rock and drill long holes for Macalloy post-tensioning bar. We may want to tighten nuts or make electrical connections. Free swimming remotely operated vehicles are excellent for inspection but cannot do anything really muscular.

I suggest that there is a need for a seabed walking vehiclerobot-machine tool which can move to a precision of a millimetre (much better than anything that can be cone with a jack-up rig) exert large forces, withstand the highest current velocities and be easily moved. Ideas for a design were described at the 2011 EWTEC conference (Salter 2011). They made extensive use of digital hydraulics. A drawing is shown in Fig. 23. 


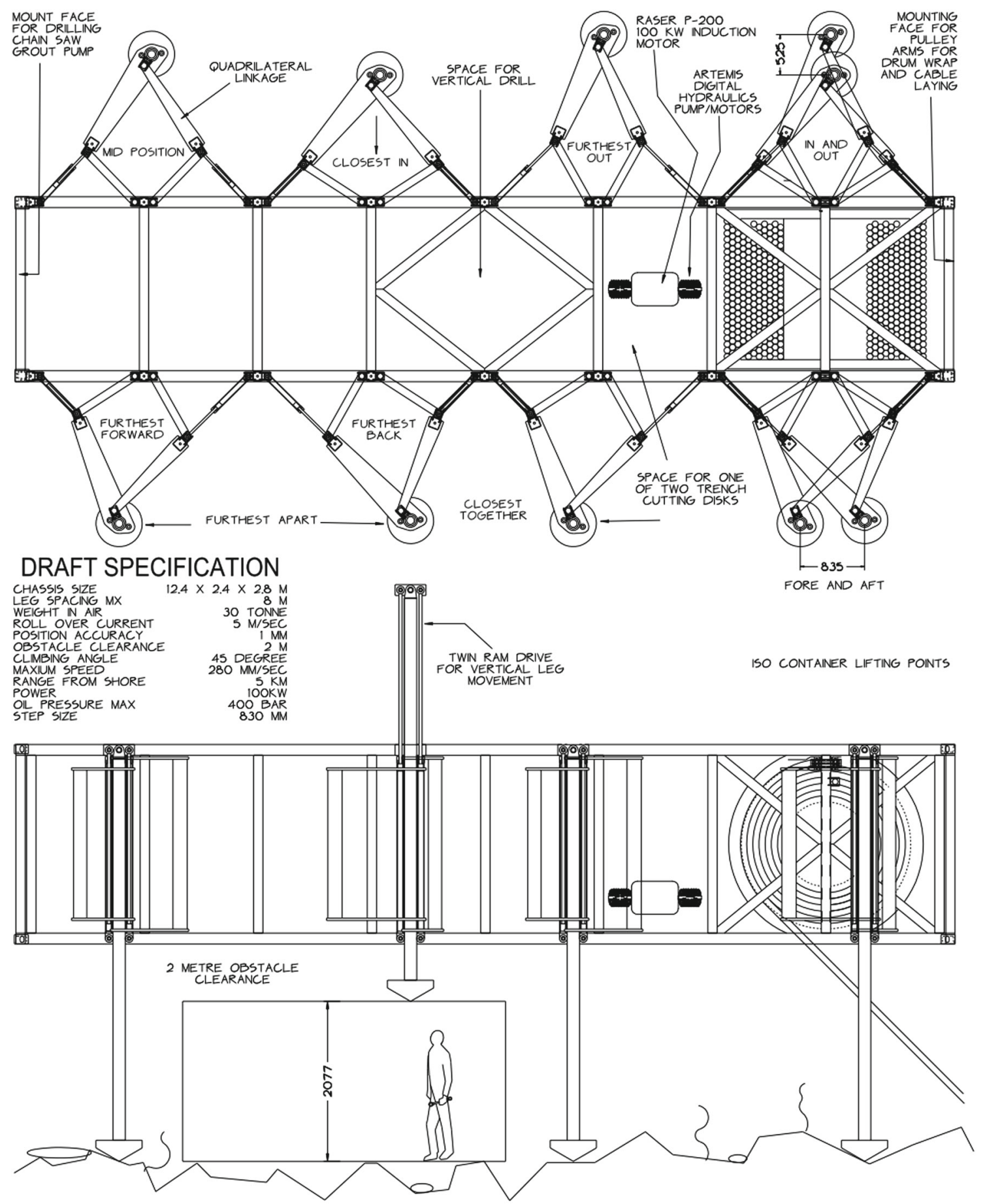

Fig. 23 Sketch views of a seabed crawler for intricate, high-force operations

The frame conforms to the ISO specification for 'fortyfoot' sea-containers, so that it can be moved anywhere quickly and cheaply. There are eight legs on quadrilateral linkages which can be driven by two hydraulic rams in the horizontal plane and one ram in the vertical plane. One side of the rams is connected to a source/sink of constant pressure at half the system pressure. The other side is connected to a digital machine which can deliver or remove a cham- ber full of oil to give a millimetre of movement or present a closed poppet valve to lock the leg. Having eight legs allows the frame to cross wide trenches and jump over large rocks. The open frame will reduce loads from waves and currents.

Ram diameter will set the force capability. Until otherwise advised a value of $430 \mathrm{kN}$ is proposed based on the specification of Admiralty tugs built in large numbers. The suggested 
power rating is $100 \mathrm{~kW}$ supplied by a cable wrapped around or paid out from a cable drum and laid in a trench cut as the vehicle walks out from land.

The most useful tools will be chain saws on a parallelogram linkage and long-hole drills but the frame will have mounting holes to allow any other attachments. The most useful instruments will be a sonar camera with 1-mm resolution, pressure transducers to tell us all the forces being exerted and microphones. Everything will be controlled by an operator, sitting warm and dry, in a Portakabin on land. None of the present developers can alone afford to fund design, but perhaps, a consortium could agree common specifications and a price which would justify building a reasonable batch of machines.

\section{Component reliability}

A painfully learned lesson has been that lengthy and very expensive delays (months and millions) can be cause by the failures of very cheap components because of misunderstandings of specification sheets or poor communications with contractors. We may be able to reduce these by testing large numbers of components and subassemblies at sea before they get joined together in a complete generating system. This could be done with a component test raft (Salter 2003, 2011) as shown in Fig. 24. It is in the shape of a ladder with large circular rungs. Components would be mounted on 'saddles' pulled against the rungs by cinches. If a cinch is loosened, the saddle can be rotated to allow inspection of parts without the risk of heavy equipment being moved by waves.

Electrical power can be taken to the raft from land. Some can be used for driving shaft seals, exercising mechanisms and testing high-voltage wet insulation. Most of the power can be returned to land, so that conductors and connectors can run at full current. We can accelerate test results by overdriving and do regular inspections at little cost. Such a facility would seem expensive for a single developer, but the entire industry would benefit if results from a common one were shared.

\section{Marine hazards}

Wave energy is often criticised because of the extreme hazards of the marine environment. This view is reinforced every time we see television pictures of extreme waves breaking over promenades and parked cars and reaching beach-front hotels. The film crews would not be able to get any images from deeper water but, if they could, they would be much more boring.

When people are asked to list the hazards of the sea, the obvious one is the size of the waves, but to complain of the dangerously high waves at a good wave site is like complaining of the high temperatures in the flame of a thermal plant. For low freeboard devices, the stresses in large waves rise at slightly less than the first power of wave height, while the available power rises with the square. The analogy in thermodynamics would be of higher temperatures giving higher Carnot efficiency. This means that the economic viability should rise in higher waves. This should not be regarded as a hostile feature. Marine currents might also be regarded as a hazard but the same arguments of power rising with the cube of velocity, while stresses rise with only the square applies. Marine current designers would dearly love higher velocities. After wave height and current velocity, there is salt. But salt is found at 28 times greater concentration on land and is thrown at high speed, mixed with abrasive gravel, at the underside of every vehicle in an attempt to overcome the serious hazard of icy roads. After salt, there are poisonous jellyfish, great white sharks, drifting icebergs, none of these common in European waters. At this point, the list usually terminates. I would like to hear from readers who can help me extend it.

The list of hostile features for land is longer and much more diverse. There is a wider range of temperatures with rapid changes between extremes combined with very poor heat transfer to still air. Air offers very little damping to resonating objects and the wind can induce much higher frequencies of oscillation. There is gravity unopposed by buoyancy with point loading rather than distributed loading. There are cliffs, gullies, crevasses, and steep gradients. There are rockfalls, mudslides, landslides, subsidence, collapsing tunnels and avalanches, volcanic explosions, lava flow, and earthquakes, none of which are anywhere nearly as predictable as bad weather at sea. Trees grow very tall but all eventually have to fall. Being under the two hundred year, tree when it comes down can be dangerous. When trees are not falling, they can be catching fire and spreading it to others. Some have thorns with poisoned spikes. There are snakes, tsetse flies, mosquitoes, river-borne bacteria, and scorpions. There are corrosive chemicals, asbestos, dioxins, mercury, heavy metals, NOX, SOX, carbon monoxide, and diesel particulates. There is abrasive gravel and sand driven at high speeds in storms. There are higher water velocities with rocks driven by flash floods. Tornadoes on land move sheets of corrugated iron, bricks and even camper vans at much higher velocities than the spray in typhoons and hurricanes at sea. Tornadoes occur more frequently and with less warning. Tidal waves and rising sea levels are danger to any coastal structure but of no concern to deepwater floating ones. Narrow gaps, traffic congestion, barbedwire, low bridges, quicksand, and marsh make it harder to move large structures on land, while there is almost no size limit in the deep sea. Electric cables on the seabed are safe from lightning, vandalism, kites, and model aircraft. Properly routed marines cables are more reliable than those on land. Planning objec- 

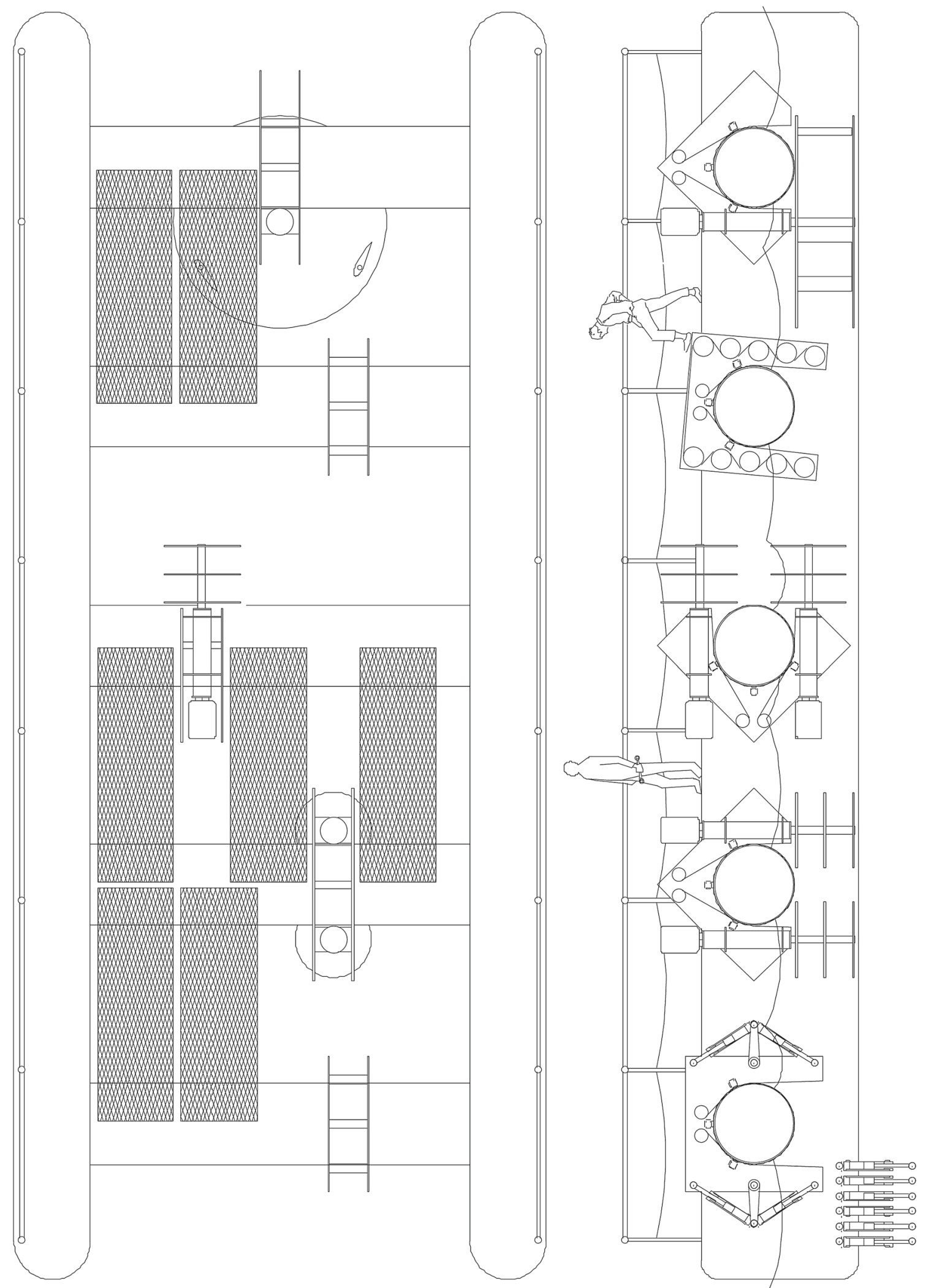

Fig. 24 The suggested design of a component testing raft. The saddles can be rotated around the rungs to allow inspection with heavy items getting loose 
tions, which are crippling onshore wind, should be fewer for distant offshore installations. You can dive from greater heights into water than on to earth, and buckets of water hurt less than buckets of stones. It is more comfortable to be under $30 \mathrm{~m}$ of water than $30 \mathrm{~m}$ of rock. Corrosion of steel in clean sea water, which is free from acidic exhaust fumes, occurs at a rate one fifth of that in the air of a damp industrial city. This can be shown by examination of the steel hulls of 19th century sailing ships abandoned in the Falklands after damage in the passage round Cape Horn and of the remains of riveted hull wreckage (built before World War II) on a beach on Islay.

There can be no doubt that our wave fields are thermally, gravitationally, flammably, structurally, meteorologically, chemically, zoologically, botanically, seismologically, tribologically, logistically, and administratively more attractive than many places on land. It was the benign marine environment that allowed life on earth to begin. The creatures that survived species extinctions were those that lived in water. The reason that some made hesitant steps to life on land was that the sea was getting too crowded. They managed to survive on land only by learning all about the dangers. Getting economical power from sea waves will be difficult and will need the very best engineering skills. I accept that conditions at sea are very different from those ashore and that every aspect must be carefully considered. However, the difficulties arise not so much from hazards at sea as from our practice of applying land-based technology to marine conditions without sufficient thought.

\section{Looking forward}

The challenge eventually must be to reduce costs of wave energy by a factor of about two. We may not be able to wait for the costs of fossil fuel generation to rise because that rise may push our construction costs up in direct proportion. However, the initial task is to ensure that early wave power devices survive and produce the output predicted by their designers, even if the first wave electricity is as expensive as the first from coal or wind.

Survival depends on full understanding of the statistics of the loads induced by waves and the strength of our parts. Every wave is a random experiment. We must understand the overlap of the upper asymptotic skirt of the load histogram and the lower skirt of the part endurance histogram. Separating them with large safety factors (which are really factors of ignorance and waste) is too expensive. If possible, we must try to clip the load skirt to the economic limit and narrow the standard deviation of the strength histogram.

Large systems can fail because of very small components. While we can do lots in computers and indoor laboratories, we must test large numbers of quite basic components, such as bearings, seals, grommets, fasteners, surface coat- ings, cables, and connectors in parallel in the chemistry and biology of the sea to know which ones will actually work. Building entire generating devices to test cheap parts, one by one, is a very expensive and very slow way to relearn the painful lessons of marine engineering. We should, therefore, have a test raft on which parts and subassemblies can be subjected to accelerated life tests.

We must try to maximise the ratio of the swept volume of any displacer to its own volume and the idle volume of the supporting structure. Low freeboards allow waves to break over a structure and so reduce, or even reverse, the mooring forces. The freeboard should, therefore, be chosen to suit the economic power limit. Concave shapes, like the corner at the foot of a breakwater or the focus of a shaped explosive charge, can amplify peak stresses in breaking waves, so everything must be convex. Sharp edges, which we see in a great many designs of wave energy device, waste lots of energy by shedding vortices, so the convexities should have a large radius like a sucked toffee.

We must realise that it will never be possible to apply a restraining force for the largest waves and that a loss of the grid connection, even one due to some event on land, will mean that sometimes we cannot apply any restraining force at all. Devices, such as nicely rounded buoys, can move an order of magnitude more than the wave amplitude and can build up very large amounts of kinetic energy which few end-stops can absorb. If we cannot use rotary mechanisms, we must provide some other means for load shedding.

When we know how to make devices survive we can start to make them more productive. It has been a long-term dream to design and test wave power devices in a computer with seamless links between the original drawing and the final results and with new ideas tried as quickly as Jamie Taylor could change models in a narrow tank. It is still a dream, but we may be getting closer.

I predict that this will show that we must overcome the instinctive preference for movements in the vertical direction. Just because vertical motions are obvious to eyes and cameras and because we have instruments to measure them and a vocabulary to name them, does not make vertical the best mode. The horizontal forces and velocities can be just as useful. Movement in a slope direction or a combination of both as in the Evans cylinder can give more than twice the power for much less than twice the cost. It is wrong to pay to resist large horizontal forces and then not get any power from them but nearly every beginner does exactly that.

Phase is the key to efficient transfer of energy. We must understand the inertia, damping, and spring of our displacing mechanisms. We want a large swept volume for waves to move into but without the spring and inertia that is the usual accompaniment, except for Even Mehlum's Tapchan and the over-toppers. Work that is put into accelerating masses or 
deflecting springs will have to be returned. Only those forces that are in phase with a velocity are useful. We must maximise damping, reduce inertia to the minimum and have only enough spring to resonate with the undesirable inertia at the most useful parts of the spectra.

We must find ways to choose and control, instant by instant, the amplitude, phase and upper limit of the force going to the power conversion mechanism. Asymmetry can shed about half the added inertia and slope reduces spring by a controllable amount. It is quite wrong to think about 'tuning' wave power devices. In radio terms, tuning is the way not to get signals from unwanted transmitters. Good wave devices would be very 'low Q' resonators with a high ratio of damping resistance to reactive impedance. We need to understand why the performance in irregular waves falls off with increasing amplitudes at a rate larger that would be predicted by non-linearity or torque and power limits of regular wave tests.

We should all use accurate common transparent costing methods, such as those developed by Tom Thorpe, based on material weight and safe working stresses. He even produced graphs of cost prediction plotted against the rate of interest, so that people could see the effect of the $15 \%$ return required of wave energy investments and compare it with the $2.6 \%$ achieved by the CEGB or the negative rates being considered in Japan and Switzerland today.

We must find ways to install and remove devices more quickly and much more cheaply than the towing methods inherited from the offshore oil industry. This may require the design of special vessels with high thrust, agile manoeuvring, instant connection, and disconnection but will not need long range.

Some wave devices may be vulnerable to currents and many marine current devices may be vulnerable to waves. Waves and current interact with one another in complicated and often dangerous ways. We must build tanks and develop software to understand the effects of these interactions.

Every new technology makes many painful mistakes. Many boilers burst, ships sank, and planes crashed before we got them reliable. The mistakes only become less painful if people learn from them. They will learn only if full details of every mistake are circulated throughout the industry. This is certainly not happening now. The requirements for raising private investment require the concealment of expensive disasters in the hope that commercial rivals will repeat the mistakes. Most of the money goes to the most convincing liars.

We must find ways to get the right amount of money to front-line engineers as and when they need it. Over-elaborate rules for tenders and contract management will not stop crooks embezzling public money, but they certainly are too complicated for honest engineers to follow unless they also have a Ph.D. in contract law. Perhaps, we should try fast and flexible agreements for people who have shown that they have earned trust with cruel and unusual punishments if they betray it.

We must have a management structure which can reach sensible decisions in a few days not a year or more. The present committee trees are designed to make the postdisaster audit trail so complicated that no individual can be identified to take the blame when things go wrong as they so often do when decisions take so long. The community needs to believe that political leaders and officials genuinely want the technology to succeed rather than appearing to want it, because they feel that this will win votes.

Acknowledgments Wave research at Edinburgh University was enormously helped by a succession of vacation students and school leavers who learned engineering skills envied by local industry in an amazingly short time. Many reported that they learned as much as from a degree and many are now senior industrialists. I cannot name several people working for the Atomic Energy Authority who risked their jobs to send us documents that were very clearly not intended for us. One included a note to say that just because I was not paranoid did not prove that they were not out to get me! The resurrection of the UK wave programme would not have occurred but for the evidence given by Gordon Senior to the House of Lords. Gordon Senior died in 2007 but will be remembered by his many friends in the wave community he saved.

Open Access This article is distributed under the terms of the Creative Commons Attribution 4.0 International License (http://creativecomm ons.org/licenses/by/4.0/), which permits unrestricted use, distribution, and reproduction in any medium, provided you give appropriate credit to the original author(s) and the source, provide a link to the Creative Commons license, and indicate if changes were made.

\section{References}

Anderson CG (1987) Optimum geometry analysis for rectangular hard magnet pairs. IEEE Magn 23:3836-3844

Artemis Intelligent Power (2016). http://www.artemisip.com. Accessed 1 June 2016

Budal K, Falnes J (1975) A resonant point-absorber of ocean wave power. Nature 256:478-479. doi:10.1038/256478a0

Clare R, Evans DV, Shaw TL (1982) Harnessing sea wave energy by a submerged cylinder device. J Inst Civil Eng 73:356-385. doi:10. 1680/iicep

Cruz J (2008) Ocean wave energy: current status and perspectives. Springer, Berlin

Cruz J, Salter SH (2006) Numerical and experimental modelling of a modified version of the Edinburgh Duck Wave Energy Device. Proc. I. Mech E. vol 220 part M. Engineering for the Maritime Environment. doi:10.1243/14750902JEME53

Evans DV (1976) A theory for wave-power absorption by oscillating bodies. J Fluid Mech 77:1-25

Evans DV, Jeffrey DC, Salter SH, Taylor JRMT (1979) Submerged cylinder wave energy device: theory and experiment. Appl Ocean Res 1:3-12

Falcão AFO, Cândido JJ, Justino PAP, Henriques JCC (2012) Hydrodynamics of the IPS buoy wave energy converter including the effect of non-uniform acceleration tube cross section. Renew energy 41:105-114

Jeffrey DC, Richmond DJE, Salter SH, Taylor JRM (1976) Edinburgh Wave Power Project second year report 
Lin (1999) Experimental studies of the hydrodynamics of a sloped wave energy device. PhD Thesis, Edinburgh University

Longuet-Higgens MS, Stewart RW (1964) Radiation stresses in water waves; a physical discussion with applications. Deep Sea Res 11:529-562

Lucas J, Salter SH, Cruz J, Taylor JRM (2009) Performance optimisation of a modified Duck through optimal mass distribution. In: 8th European Wave and Tidal Stream Conference. Uppsala

McConnell J (1983) Comparative Fatigue Tests on 3 Core 22kV AC Submarine Cables for Floating Wave Energy Converters. Pirelli project, p 8526

Payne GS, Taylor JRM, Parkin P, Salter SH (2006) Numerical modelling of the sloped IPS buoy wave energy converter. In: Proceedings of the Sixteenth International Offshore and Polar Engineering Conference, International offshore and polar engineering conference by ISOPE, pp 396-402

Pizer D (1994) Numerical modelling of wave energy absorbers. Edinburgh wave project report

Salter SH (1988) Evidence to the House of Lords Select Committee on European Communities. Alternative Energy Sources. 16th report. HL Paper 88:190-206

Salter SH, Rampen WHS (1993) The Wedding-cake Multi-eccentric Radial-piston hydraulic machine with direct computer control of displacement. In: 10th International Conference on Fluid Power. Bruges

Salter SH, Rea M (1984) Hydraulics for wind. European Wind Energy Conference, pp 534-541

Salter SH, Lin C-P (1995) The sloped IPS Wave energy Converter. In: Second European Wave Energy Conference Lisbon, pp 337-334

Salter SH (2012) Are nearly All Tidal-stream turbine designs wrong? In: 4th International Conference on Ocean Energy. Dublin

Salter SH, Taylor JRM, Caldwell NJ (2002) Power Conversion Mechanisms for Wave Energy. Proc Inst. Mech. Eng. Part M, Engineering for the Marine Environment
Salter SH (1985) Wave powered desalination, conference on energy for rural and island communities. In: Twidell $\mathbf{J}$ (ed). Pergamon, Oxford, pp 235-241

Salter SH, Cruz JMBP, Lucas JAA, Pascal RCR (2007) Wave powered desalination. International conference on integrated sustainable energy resources, Abu Dhabi

Salter SH (2009) A 20 GW Thermal 300-metre3/sec wave-energised, surge-mode nutrient-pump for removing atmospheric carbon dioxide, increasing fish stocks and suppressing hurricanes. In: 8th European Wave and Tidal Conference. Uppsala

Salter SH (2011) Two impediments to wave energy and ideas for removing them. In: European Wave and Tidal Energy Conference Southampton

Salter SH (2003) Proposals for a component and sub-assembly test platform to collect statistical reliability data for wave energy. In: 4th European wave and Tidal Energy Conference Cork

Skaf K (2012) Drop box. http://www.dropbox.com/sh/c852tpue32 fr5iy/nQDRPbSO_p. Accessed 1 June 2016

Skyner D (1987) Solo duck linaer analysis. Edinburgh Wave Power Project Report

Taylor JRM (1984) Bending moments in long spines. Edinburgh Wave Power Report

Whitney LD, Hobgood JS (1997) Relationship between sea-surface temperature and maximum intensities of tropical cyclones in the eastern north pacific ocean. Am Meteorol Soc J Clim 10:29212930

Young HE, Pollock J (1985) Variable coefficient control of a wave energy device. Edinburgh Wave Power Project Report 